\title{
Importancia de la genealogía aplicada a estudios genéticos en Costa Rica
}

\author{
Mauricio O. Meléndez Obando \\ Asociación Costarricense de Genealogía e Historia (ASOGEHI) y Academia Costarricense de Ciencias Genealógicas \\ (ACCG), San José, Costa Rica. Correspondencia: Apartado postal 1771-1002, Paseo de los Estudiantes, San José, \\ Costa Rica.momo64@costarricense.cr
}

Recibido 16-VII-2004. Corregido 24-VIII-2004. Aceptado 17-VIII-2004.

\begin{abstract}
The importance of genealogy applied to genetic research in Costa Rica. The extensive development of genealogical studies based on archival documents has provided powerful support for genetic research in Costa Rica over the past quarter century. As a result, several questions of population history have been answered, such as those involving hereditary illnesses, suggesting additional avenues and questions as well. Similarly, the preservation of massive amounts of historical documentation highlights the major advantages that the Costa Rican population offers to genetic research. Rev. Biol. Trop. 52(3): 423-450. Epub 2004 Dic 15.
\end{abstract}

Key words: Genealogy, genetics, population, archives, Costa Rica.

Palabras clave: Genealogía, genética, población, archivos, Costa Rica.

El uso de la genealogía en otros campos del conocimiento y de la cultura en las últimas décadas ha alcanzado importantes desarrollos junto a la demografía histórica, la historia política, la historia social, la prosopografía -o biografía colectiva-, la historia de la mentalidades, la biología, la epidemiología, la antropología, el derecho, la literatura y más recientemente la genética (Meléndez Obando 2000).

Solo en Costa Rica, la genealogía se ha empleado en estudios genéticos como la sordera de los Monge, la enfermedad bipolar, la migraña, la amiloidosis familiar dominante, la esquizofrenia, la enfermedad de Charcot Marie Tooth, el mal de Gilles de Turete, la migraña y la caracterización étnica de la población costarricense, entre otros (Meléndez Obando 1999, 2000) (ver Cuadro $N^{\circ} 1$ ).

Trabajos como los de Bernal Morera sobre ADN mitocondrial para caracterizar étnicamente a las compañeras de algunos conquistadores de Costa Rica, cuyos resultados más recientes comprueban las suposiciones de historiadores y genealogistas (Morera et al. 2004), y estudios como los del mismo Morera y Ramiro Barrantes sobre el mestizaje en Costa Rica mediante modernas técnicas para los estudios genéticos, demuestran el alcance recíproco de las ciencias biológicas y la genealogía (Morera y Barrantes 1995, Morera et al. 2001, 2003).

Asimismo, investigaciones pioneras como las de Henriette Raventós, Pedro León Azofeifa, Mary-Claire King y Eric Lynch sobre la sordera de los Monge de Taras de Cartago, en Costa Rica (León et al. 1981, 1992, Lynch et al. 1997) y las más recientes sobre la enfermedad bipolar (o maniaco depresiva), y la esquizofrenia en los que trabajan las costarricenses Mitzi Spesny, Henriette Raventós y otros científicos nacionales y extranjeros (Escamilla et al. 1996, Mathews et al. 2004), han requerido de la participación activa de genealogistas (Eduardo Fournier, en el primer y segundo caso, y Ramón Villegas, en el segundo y en el tercero).

Más recientemente el proyecto en desarrollo "La herencia de longevidad inusual: un 


\section{CUADRO 1}

Principales estudios genéticos en Costa Rica

\section{Enfermedad estudiada}

Sordera de los Monge (enfermedad progresiva)

Enfermedad bipolar (en su variante más severa la persona pasa de la depresión profunda a la manía)

Migraña (jaqueca o dolor de cabeza intermitente)

Amiloidosis familiar dominante (enfermedad degenerativa que se inicia antes de los 30 años y causa daño generalizado y muerte)

Esquizofrenia (enfermedad mental que pude conducir a una demencia

Genes susceptibles a la adicción (esta es una hipótesis de trabajo)

Proyecto mundial del Genoma Humano

(descripción general del genoma humano)

Charcot Marie Tooth (causa debilidad progresiva de los músculos de pies, muslos y antebrazos, entre otros males)

Caracterización étnica de la población costarricense mediante marcadores genéticos

Gilles de la Turete (desorden neurosiquiátrico que provoca movimientos involuntarios a nivel motor y bocal -conocidos como tics-)

Caracterización étnica de las compañeras de los conquistadores de Costa Rica

La herencia de longevidad inusual: un estudio diacrónico

Glaucoma primario de ángulo abierto

Fuente: Pedro León Azofeifa, Mitzi Spesny y Ramón Villegas.
Institución a cargo

CIBCM-UCR y Universidad del Estado de Washington (EE.UU.)

CIBCM-UCR y Universidad de California

(San Francisco, EE.UU.)

CIBCM-UCR y un grupo holandés

CIBCM-UCR

CIBCM-UCR y Universidad de Texas (EE.UU.)

CIBCM, Universidad de California (EE.UU.) e Instituto de Alcoholismo y Farmacodependencia (IAFA).

CIBCM-UCR

Bernal Morera, Alejandro

Leal y Gerardo del Valle

Escuela de Biología,

Universidad de Costa Rica

Luis Diego Herrera Amighetti y CIBCM-UCR

Bernal Morera Brenes

Lorena Madrigal (Universidad del Sur de la Florida)

Gabriela Chavarría Soley estudio diacrónico", a cargo de Lorena Madrigal, de la Universidad del Sur de la Florida, y en el que participan antropólogos, genetistas y genealogistas, es un claro ejemplo de esta interdisciplinariedad (Madrigal 1999).

El objetivo de este artículo es revisar el desarrollo de los estudios genealógicos, basados en fuentes documentales primarias, en apoyo de la investigación genética en Costa Rica durante el último cuarto de siglo, y cómo tal interacción ha permitido responder algunas interrogantes sobre la historia poblacional, sobre varias enfermedades hereditarias y ha dejado vislumbrar la de otras, e ilustrar las enormes ventajas potenciales de esta población como modelo para los estudios genéticos.

\section{ORÍGENES DE LOS COSTARRICENSES}

Según los científicos, el hecho de que los orígenes de los costarricenses actuales se hallen en un reducido núcleo de personas hace poco más de 440 años, cuando los conquistadores se 
mezclaron con indias y mestizas, principalmente, hace que este tipo de investigaciones en Costa Rica sea muy atractivo.

De acuerdo con las cifras que da Meléndez Chaverri (1982), de 1561 a 1599 ingresaron al Valle Central costarricense 478 personas, de las cuales 86 se convirtieron en fundadoras (de estas, 19 son casos dudosos). Sin embargo, de los fundadores que cita Meléndez Chaverri habría que eliminar 3 que definitivamente no dejaron descendencia en Costa Rica y añadir 16 (algunos igualmente dudosos), lo que hace ascender la cifra de fundadores a 102 durante el siglo XVI (Apéndice $\mathrm{N}^{\circ} 1$ ). Por supuesto, si se considerara a cada español que arribó en este periodo, la cifra subiría considerablemente pues algunos de los que se consideran fundadores llegaron con hijos varones y mujeres, como Alonso del Cubillo y Juan de Peñaranda, los cuales no están cuantificados aquí.

La definición de "fundador" utilizada por Meléndez Chaverri (1982) y respetada en la anterior estimación, es restrictiva a lo que él considera como fundadores de la sociedad costarricense de cultura hispana, o el embrión del Estado de Costa Rica, y restringida a un límite superior definido en forma arbitraria (1599). Si la fecha se ampliara, también antojadizamente a 1650, en función de la abundancia documental disponible, el número de "españoles fundadores" que contribuyeron con genes a la población actual de Costa Rica probablemente se triplicaría.

Además, dichas cifras no incluyen a los fundadores amerindios ni africanos (también conquistadores), de quienes nos consta su existencia grupal mas no podemos identificarlos individualmente, pero tampoco a las mujeres, que Meléndez Chaverri no considera explícitamente como fundadoras (salvo cuando habla de "personas-familias").

León y Fournier (2000) afirman: "El Valle Central es colonizado por unas 83 ? familias españolas que se mezclaron racialmente con los amerindios y con un número pequeño de africanos provenientes del Caribe".

Sin embargo, hay varios aspectos de tal afirmación que debemos retomar para dejar abierta una discusión futura más profunda. En primer lugar, los conquistadores arribaron invariablemente sin compañía femenina, por lo que no podemos hablar de familias españolas, aunque excepcionalmente las hubo, en estos casos casi siempre establecidas cuando los indígenas habían sido sometidos; por ejemplo, Alonso del Cubillo, natural de Segovia, en Castilla La Vieja, pasó a Costa Rica con su mujer, doña Isabel Ruiz de Villatoro, también de España, e hijos (Galbis Díez 1986); lo mismo que Juan de Peñaranda, natural de la villa de Talamanca, en Castilla La Nueva, su esposa, Sabina de Artieda, también española, y su hijos (Fernández 1907); y Juan Solano, natural de Trujillo, en Extremadura, quien viajó a Panamá, donde casó con doña Mayor de Benavides, natural de Jerez de los Caballeros, Andalucía, y regresó con ella a Cartago (AGN. Inquisición, Vol. 279, Exp. 7, f. 62 e Inquisición, Vol. 366, Exp.1, f. 1).

Por otra parte, no se ha podido establecer plenamente el origen peninsular de la mayoría de los conquistadores que dejaron descendencia en Costa Rica ni tampoco de sus esposas o compañeras; de las 478 personas contabilizadas por Meléndez Chaverri (1982) que ingresaron entre 1561 y 1599 , solo pudo determinar la procedencia de 63; es decir, apenas un $13.20 \%$ del total. De esos 63, el 55.55\% (35) provenía de España, el 34.92\% (22) procedía de otras partes de América y el 9.52\% (6) de otros países de Europa.

Se sabe además que hubo conquistadores afromestizos (Meléndez Chaverri 1982) y debe haberlos habido mestizos aunque esto no se ha podido corrobar. Solo para ejemplificar, veamos cómo estaban conformadas las huestes de Cavallón y Vásquez de Coronado; el primero venía con 80 soldados españoles y negros (Peralta 1883) y con indios sacados de la provincia de Nicaragua (Meléndez Chaverri 1982), el segundo ingresó con 80 soldados y vecinos desde León de Nicaragua (Meléndez Chaverri 1972), también con indios sacados de la citada provincia (Fernández, 1883, III: 53) y luego contaron con ayuda de los indios del Valle Central en otras incursiones (Meléndez Chaverri 1972). 
En realidad, las primeras uniones entre conquistadores y las amerindias que habitaban el Valle Central fueron casuales y ninguna devino en matrimonio formal (al menos no quedó prueba de ello). Así, por ejemplo, los siguientes conquistadores dejaron hijos cuyas madres fueron indias: Antonio Alvarez Pereira y Domingo Jiménez. En los siguientes casos lo suponemos pues de haber sido españolas, no se habrían omitido sus nombres en las pruebas de méritos y servicios: Sebastián López de Quesada y Esteban de Mena.

Meléndez Chaverri (1982) también excluyó de la categoría de "fundadores" a los nativos locales que mantuvieron el estatus de "población indígena", y que gracias al proceso de mezcla dieron luego origen a la creciente población mestiza, ampliamente mayoritaria en el siglo XVIII (Gudmundson 1978, Morera y Barrantes 1995, Barrantes y Morera 1999). Pese a la debacle demográfica de la población indígena tras el arribo de las huestes conquistadoras, es difícil imaginar que los 21199 indígenas encomendados en 1569 por Perafán de Ribera (Quirós 1990) hayan desaparecido sin dejar huella. Tampoco creemos que hayan desaparecido todos los negros conquistadores -la mayoría esclavos- que acompañaban a sus amos en las entradas contra los indios, como tampoco los indios de otros territorios que ingresaron con los primeros conquistadores; de estos últimos, Meléndez Chaverri (1982) cita que en 1623 todavía vivía uno de esos conquistadores indios llamado Andrés Núñez Suazo. En ambos casos, la pérdida documental y su posición en la base de la pirámide social impidieron que quedaran pruebas que permitan trazar claramente su descendencia.

Entonces, el núcleo fundador de que hablan Meléndez Chaverri (1982), León y Fournier (2000) es la élite que se ha podido reconstruir con base en los documentos existentes, pero de ninguna manera creemos que sea el total. De hecho, la mayoría de la información se refiere a los grupos que Meléndez Chaverri (1982) denomina superior y medio (gobernador, sus tenientes, corregidores, oficiales, encomenderos, alguaciles mayores, sargentos mayores, estancieros, ganaderos, mercaderes, escribanos, tenientes de corregidor, tenientes y capitanes y oficios de cabildo), mientras que del inferior (integrado por los soldados, artesanos y gentes de los oficios llamados bajos) queda poca evidencia documental, que el mismo autor reconoce (1982).

Además, Meléndez Chaverri explica (1982) que algunos conquistadores de origen "bajo" lograron ascensos sociales por el mero hecho de convertirse en fundadores en las nuevas tierras conquistadas; esto se debía a que la hidalguía podía obtenerse por el valor y los servicios que se prestaran al rey (Sanchiz 1976).

En cuanto a la pérdida documental, por ejemplo, toda la serie de protocolos anteriores a 1607 se perdió irremediablemente (Chacón 2000) y la serie sacramental anterior a 1593 no existe (Fournier y Vega, sin fecha); además, todas la series documentales del siglo XVI están incompletas.

Meléndez Chaverri (1982) tampoco consideró como "fundadores" a los cientos de esclavos africanos que ingresaron al territorio durante todo el periodo colonial. La trata esclavista aumentó considerablemente en Costa Rica desde mediados del siglo XVII hasta la primera cuarta parte del siglo XVIII, cuando disminuyó tras la caída del comercio cacaotero (Meléndez Chaverri y Duncan 1989). La contribución genética de este grupo a la población general, hispana o hispanomestiza actual ha sido directa e indirectamente documentada por estudios históricos (Gudmundson 1978), genealógicos (Meléndez Obando 1993, 1997) y genéticos (Saenz et al. 1974, 1980, Madrigal et al. 2001, Morera et al. 2001, 2003).

Finalmente, en algunos estudios científicos se ha afirmado que el grupo fundador creció con poca afluencia de nuevos genotipos hasta finales del siglo XIX (León y Fournier 2000). Dicha afirmación amerita una cuidadosa evaluación demográfica pues es producto más de la intuición que del análisis cuantitativo, de modo que queda abierto para una detallada discusión futura. Ciertamente, durante todo el periodo colonial los inmigrantes más numerosos fueron los españoles, otros americanos 
(criollos, mestizos y mulatos) y los africanos (Sanabria 1957); en general, todos estos inmigrantes arribaron de manera lenta pero constante hasta 1821; en ese mismo lapso, ocasionalmente arribaron personas de otros países europeos. Asimismo, durante este periodo, la mezcla racial (entendemos aquí raza en su sentido histórico, no peyorativo, pues es harto conocido que los humanos integran una sola raza) fue un continuum que se prolonga hasta la actualidad (Meléndez Obando 1997).

Poco importa si eran unos 100 o 5000 fundadores, la cuestión es que, relativamente, no eran muchos. Por eso, el hecho de que alguno(s) de ellos pudieron haber introducido un gen defectuoso, que se dispersó en la población, por diversos procesos evolutivos, hace que este tipo de investigaciones en Costa Rica sea muy atractivo.

\section{FUENTES PARA LA INVESTIGACIÓN GENEALÓGICA}

La genealogía en su sentido más básico consiste en la serie de progenitores y ascendientes de una persona o en la serie de descendientes de un individuo o una pareja. En el primer caso, estamos hablando de genealogía ascendente y en el segundo, de genealogía descendente (Sampedro 1999). La ignorancia de algunas personas, incluso académicos, resta valor a la genealogía en su sentido básico (listados de ascendientes o descendientes, vinculados mediante matrimonios o bautizos), pero precisamente este es su principal apoyo para los trabajos genéticos, en que se intenta conocer cuál es el vínculo familiar de dos personas que portan la misma enfermedad (u otro tipo de característica), para tratar de determinar quién o quiénes pudieron haberla transmitido.

En un sentido más amplio, es la disciplina llamada a desentrañar la historia de los antepasados de una persona, o sus descendientes, tratando de contextualizar sus vidas en la época que les correspondió vivir. Los mormones emplean el término "historia familiar", muy útil para referirse a la genealogía que va más allá de un esquema genealógico básico, que nos dice solamente cuándo nacieron, casaron y murieron las personas en estudio.

Ahora bien, independientemente del abordaje epistemológico que se haga de ella, es decir, sin importar si se le considera una ciencia independiente o auxiliar de la historia, un simple pasatiempo o una obligación moral o religiosa con los antepasados, la genealogía cuenta con fuentes bien determinadas en las que se debe investigar rigurosa y críticamente (Meléndez Obando 2000). Para profundizar más sobre estos conceptos y otros temas genealógicos (ver Apéndice $\mathrm{N}^{\circ} 2$ ).

Las fuentes en que podemos hallar la información genealógica se dividen en primarias y secundarias (ANCR-ASOGEHI 2002). La fuentes primarias la conforman todos aquellos documentos manuscritos custodiados en archivos o aquellos documentos impresos que reproducen información original aunque hayan sido publicados mucho tiempo después de haberse escrito. Las fuentes secundarias o bibliográficas las conforman todos aquellos libros o artículos que tratan del tema que se investiga o se relacionan con este.

En el caso de la genealogía, además, se debe considerar seriamente la tradición oral pues los miembros de una familia (sobre todo los más viejos) pueden conocer información que nunca se hallará en las fuentes oficiales (que son las que casi siempre custodian los archivos), pero, además, deben tenerse en cuenta otras fuentes materiales, generalmente custodiadas en las familias, como recordatorios, invitaciones, diarios de vida y fotografías.

\section{ARCHIVOS}

En Costa Rica, las fuentes primarias más antiguas para la investigación genealógica las hallaremos en los archivos eclesiásticos y los civiles. El principal archivo eclesiástico del país es el Archivo Histórico Arquidiocesano Bernardo Augusto Thiel (ABAT, en adelante; antes Archivo Eclesiástico de la Curia Metropolitana), pero también están todos los 
archivos parroquiales; entre los civiles, contamos con el Archivo Nacional de Costa Rica (ANCR, en adelante), el Registro Civil y los archivos de los cementerios.

De la misma manera, en cada archivo se custodia diversa tipología documental de interés fundamental para la reconstrucción genealógica. En el ABAT y en los archivos parroquiales en general, se custodian las series sacramentales (bautizos, confirmas, matrimonios y defunciones) y los expedientes matrimoniales; además, en el ABAT se hallan juicios eclesiásticos, ordenaciones, cofradías y capellanías, entre otros. El ABAT es el mejor archivo histórico de carácter eclesiástico en toda Centroamérica, tanto por su calidad documental (se conservan originales de fines del siglo XVI en adelante) como por los criterios técnicos aplicados en sus depósitos documentales, pese a que no cuenta aún con un verdadero taller de restauración; asimismo, mediante un convenio con la Iglesia de Jesucristo de los Santos de los Ultimos Días (mormones) se microfilmaron las series sacramentales de casi todo el país. Los centros de historia familiar de las iglesias mormonas cuentan con copias de esta documentación, así como del Registro Civil (todo hasta 1930, aproximadamente), que se pueden consultar libremente (IJSUD sin fecha, Meléndez Obando 1994).

Por su parte, el ANCR, fundado en 1888, resguarda también documentación que data del siglo XVI en adelante; los servicios de este archivo son buenos salvo la calidad de algunas microfilmaciones y la ausencia de una sala de lectura de microfilmes adecuada. En la serie de protocolos notariales se pueden hallar testamentos, poderes para testar, compraventas, reconocimientos de deudas, emancipaciones, cartas de dote, reconocimiento de capellanías, donaciones, escrituras relacionadas con esclavos -compras, ventas, manumisiones, etc.- y reconocimiento de hijos; también existen padrones, censos y pleitos judiciales (Chacón 2000).

Por último, en el Registro Civil, se puede encontrar información de nacimientos, matrimonios y naturalizaciones a partir de 1888, año de su creación.

Por supuesto, la información de estos archivos se complementa, y si se quiere una genealogía lo más completa posible, se debe investigar en todos ellos.

Sobra decir que en cualquier trabajo genealógico que se pretenda presentar como serio -sobre todo a nivel académico- la consulta de fuentes primarias y en su defecto, secundarias, no es opcional, es requisito obligatorio. (Una propuesta de lo que debe ser la genealogía en el siglo XXI, se puede ver en Meléndez Obando 2000).

\section{ALGUNOS EJEMPLOS DOCUMENTALES}

Como se dijo, los documentos recogen información sumamente importante para la reconstrucción genealógica, pero también brindan datos que pueden resultar fundamentales en estudios biomédicos, por esta razón, veremos algunos ejemplos concretos -no se trata de un análisis exhaustivo de las fuentes- y cómo estos permiten establecer filiaciones o conocer detalles de otra índole.

Asimismo, la pérdida documental se ha dado en todos los archivos, por lo que no resulta extraño que no hallemos bautizos o matrimonios, en las series sacramentales, pero a veces se debe también a que algunos sacerdotes no eran tan rigurosos en el registro de los sacramentos de sus feligreses. También hemos tenido la oportunidad de consultar listados que se elaboraron en el siglo XVIII por las autoridades provinciales (civiles) y algunos de los documentos ahí reseñados ya se habían perdido antes de la fundación del ANCR.

Sin embargo, pese a los vacíos documentales, Costa Rica cuenta con los mejores registros históricos de Centroamérica, lo que permite trazar genealogías muy completas, tanto en las filiaciones que se logran establecer como en la historia vital de los antepasados de los costarricenses. 
La serie de bautizos representa la más voluminosa de las sacramentales en cualquier parroquia; las más antiguas del país (Cartago) se perdieron y solo quedaron algunas de 1594 , fecha a partir de la cual la serie se ha conservado más o menos de manera continua, con varias lagunas.

Pese a que los curas tenían la obligación de anotar cuidadosamente la información de los padres y abuelos, según lo establecía el Concilio de Trento, lo segundo solo se hizo en algunos periodos y no en todas las parroquias; asimismo, durante el periodo colonial casi siempre se anotaba la categoría sociorracial a la que pertenecían las personas.

Asimismo, la anotación de las categorías sociorraciales durante el periodo colonial, aunque no siempre constante ni con el mismo significado, permite hacer análisis aproximativos de la evolución demográfica de los diferentes grupos raciales y su grado de mestizaje. Con las categorías sociorraciales se pretendía ordenar, a la luz de una corriente taxonómica, una realidad fenotípica extremadamente variable en los seres humanos (Meléndez Obando 2003). Por una parte, los factores biológicos, como color de la piel y del cabello, se expresaban en tiempos coloniales por las diferencias étnicas (o "raciales", en un sentido tradicional del término), según las cuales se estructuraba la sociedad en tres grupos básicos: españoles -criollos o peninsulares-, indios y negros; y sus mezclas: mestizos, mulatos y zambos, entre otras, conocidas más como "castas" (Morera y Barrantes 1995, Meléndez Obando 2003).

Los españoles ocupaban las máximas posiciones como portadores de la pureza de sangre y el honor, entre otros elementos, mientras los demás sectores estaban por debajo de ellos, y en la posición inferior se tenía a los negros esclavos y sus descendientes, a quienes estaba vedado, según las leyes, cualquier posibilidad de ascenso a la cúspide. Pero, por otra parte, a los factores biológicos se asociaban elementos socioeconómicos como el honor, la vestimenta, la lengua, el trabajo, las relaciones de influencia y el poder económico, que fortalecían las separaciones raciales de los grupos (Meléndez Obando 2003). Precisamente, esos elementos socioeconómicos hicieron mucho más compleja la estratificación pues mediante el lento ascenso de las castas, y en particular de los afrodescendientes, a mejores posiciones (acceso a la vestimenta, la lengua, el trabajo y el dinero que originalmente tenían solo los españoles) tornó relativas las divisiones sociorraciales (Meléndez Obando 2003), por eso afirmamos que estudios en este sentido darán resultados tan solo aproximativos.

Ahora, veamos algunos ejemplos de documentos sacramentales [se hizo transcripción literal en todos los casos]:

[Al margen izquierdo: "Bonifacio español"]

"En Villa Viexa, a los catorze dias del mes de mayo del año de mil setecientos ochenta y sinco, yo, don Juan Manuel Corral, notario del Santo Oficio, cura por su Magestad Real de la iglesia parroquial de dicha villa, baptize solemnemente a Bonifacio, hijo legitimo de don Joseph Gregorio Trejos y de doña Maria Vogantes, avuelos paternos don Raphael Trejos y Rosa Nuñes, maternos, don Matias Vogantes y doña Rosalia Porras; nacio esta criatura el dia doze de dicho mes; fue su padrino Joseph Blas Vogantes, a quien adverti su obligacion y parentesco espiritual y para que conste lo firmo Juan Manuel Corral, rubricado" (ABAT. LBH Nº10, f. 130, a. 199).

[Al margen izquierdo: "Maria mestisa"]

"En Villa Viexa, a los veinte y seis de junio del año de mil setecientos ochenta y sinco, yo, don Juan Manuel Corral, notario del Santo Oficio, cura por la Magestad Real 
de la iglesia parroquial de dicha villa, baptice solemnemente

a Maria, legitima de Trinidad Espinosa y de Loren-

za Ramires; avuelos paternos no conocidos; maternos, Damian

Ramires y Gertrudis Monje; nacio esta criatu-

ra el dia veinte y sinco de dicho mes; padrinos:

Ignacio Caraballo y Maria Aralla, a quien adverti

su obligacion y parentesco espiritual y para

que conste lo firmo

Juan Manuel Corral, rubricado" (ABAT. LBH Nº10, f. 140, a. 259).

[Al margen izquierdo: "Maria de las Niebes mulata parbula"].

"En Villa Vieja, en quatro dias del mes de julio

de mil setecientos ochenta y ocho años, yo, don

Onofre Ramires, teniente de cura, puse oleo y

chrisma y baptise solemnemente a Maria de

las Niebes, mulata, hija lexitima de Joseph Antonio

Zamora y de Brigida Sandobal; fue ma-

drina Candelaria Umaña, a quien adber-

ti su obligacion y lo firmo

Josef Onofre Ramirez" (ABAT. LBH N¹0, f. 174, a. 233).

En cuanto a los matrimonios, igualmente, los más antiguos del país se han perdido y se conservan de manera más o menos continua a partir de 1662; quizá uno de los peores escollos se refiere a que en algunas parroquias y en distintos periodos, los curas no anotaron los nombres de los padres de los contrayentes, lo que, para los casos del siglo XVIII, generó vacíos difíciles de llenar.

En la reconstrucción genealógica, las series sacramentales son las más empleadas pues en pocas líneas se anota abundante información relacionada con parentescos. Por ejemplo, casi siempre en las partidas de matrimonio consta el nombre de los contrayentes y el de sus respectivos progenitores; además de los padrinos; a partir de fines del siglo XIX se añaden datos como ocupación y lugar de nacimiento.

Veamos algunos ejemplos:

[Al margen izquierdo: "Andres de lovo y Isabel de los Santos"].

"[Cartago] En _inco de septiembre de mill y seiscientos y

sesenta y siete años, aviendo preçedido

lo dispuesto por el santo concilio, des-

pose y vele segun orden de nuestra santa

Madre Iglesia a Andres de Lovo, natu-

ral de Guathemala, con Isabel de

los Santos, hija natural de Juan de

Vinda y de Maria Camelo. Padrinos

Zelidon de hortega y Leonor de Ortega

testigos Don Marcos de Salaçar i Sebastian Peñaranda

D Domingo de echabarria, rubricado" (ABAT. LMC N¹, f. 003 a. 012).

[Al margen izquierdo: "Bentura con Magdalena desposados y velados"]

"[Cartago] En treinta de nobiembre de mil seiscien-

tos y sesenta i nuebe años, despose y vele se-

gun horden de nuestra Santa Madre Iglessia

a bentura de Coto mestiso natural desta

çiudad abiendo corrido las tres amonesta-

çiones con que dispone el Santo Concilio de 
Trento con Maria Magdalena mulata natural desta çiudad. Fueron padrinos Diego Solano i Juana Peres, testigos Mateo Ortis i Domingo sacristanes.

Augustin de Torres, rubricado" (ABAT. LMC N¹, f. 25, a. 111).

[Al margen izquierdo: "Joseph Antonio Arrieta, indio naborio, con Victoria Palma, mulata libre, casados y velados"].

"En veinte y siete dias del mes de henero y mil septesientos y quarenta años, aviendo precedido las tres amonestaciones y no resultado [sic] ympedimento y estando asimismo desposado, vele infacie eclesie a Joseph Antonio Arrieta, hyndio naborio, hijo de Manuela Arrieta, con Victoria Palma, mulata libre, hija de Paula de las Salas; fueron padrinos Dionicio Berrocal y Juliana Cayetana Ocampo; testigos [sic]: Esteban Melendes y para que conste lo firmo.

Eusebio Melendes, rubricado" (ABAT. LMSJ Nº1, f. 7, a. 04).

[Al margen izquierdo: "Joseph Santiago Barbosa con Antonia Josepha Artavia, desposados y velados"]. "Yo, don Manuel Antonio Chapui de Thorres, cura por el Real Patronato de esta Santa Iglesia Parrochial de señor San Jospeh de Aserri, en dose del mes de febrero del año de mil setesientos setenta y seis, haviendo corrido las tres proclamas ynter missarun solemnia, segun orden el Santo Consilio de Trento y no resultando ympedimento alguno despose y vele yn facie eclesia a Joseph Santiago Barbosa con Antonia Josepha Artavia; fueron padrinos Joseph Mariano Valerio y Josepha de los Reyes Valerio; testigos: don Balthasar de Mora y Francisco Palasios y para que conste lo firmo Manuel Antonio Chapui, rubricado" (ABAT. LMSJ Nº1, f. 161, a. 062).

[Nota: Obsérvese que en este caso se omitieron las categorías sociorraciales de los contrayentes].

Finalmente, la serie de defunciones es quizá la que brinda información más pobre pues muy a menudo solo consta el nombre del difunto y el de su cónyuge (dependiendo de la parroquia, hay casos en que solo consta el nombre del difunto, sin más datos, lo que dificulta establecer con certeza de quién se trata; por supuesto, se pueden ver excepciones, donde se anota, además del nombre del difunto, el de sus padres, el de su cónyuge y hasta la causa de muerte).

Veamos algunos ejemplos:

[Al margen izquierdo: "Don Estevan de la Riva Aguro (sic) adulto"]

"En la ciudad de Cartago en diez y nuebe dias del mes

de septiembre de mill setezientos y treinta y nuebe años, mu-

rio Don Estevan de la Riva Agüero hijo lexitimo de

Don Antonio de la Riva Agüero difunto y de doña

Chatalina Arburola haviendo rezibido solamente el santo

sacramento de la penitensia por no averle dado

tiempo para los demas su apresurada muerte en-

terrose en la Santa Iglessia Parroquial, y para

que conste lo firme

Jph Migl de Guzman i chavarria, rubricado" (ABAT. LDC N¹, f. 19 v., a. 179). 
“[Cartago] Manuel Garzia Negro esclavo de Doña Rita Garzia de Argueta murio el dia primero de febrero [1745], haviendo recivido los Santos Sacramentos, se enterro en esta Santa Iglesia Parrochial el dia dos de dicho mes y año y para que conste lo firmo. Fray Joseph Gusman y Portocarrero, rubricado" (ABAT. LDC N¹, f. 44, a. 466).

[Al margen izquierdo: "Adulto Manuel Estrada"]

"En esta Iglesia de Santo Domingo [de Heredia] a trese de abril del año de mil ochocientos cincuenta y cuatro, yo, el presbitero Jose Prieto, teniente de cura di seputura eclesiastica a Manuel, hijo lejitimo del señor Manuel Estrada y Bartola Sisnero, vecino de la Provincia de San Jose y esposo de la señora Josefa Roman, se confeso lo que firmo [no está la firma del cura]" (ABAT. LDSDH, 1849-1854, f. 16, a. 139)

[Al margen izquierdo: "N 11 Calletano Fallas adulto esposo de Felipa Mora"] "En la parroquia de Aserri, a diez i siete de mayo de mil ochocientos setenta y ocho, yo, el presbitero Rafael B. de J. Chinchilla, cura interino de esta Santa Iglesia, [testado: Bautizé solemenemente] di sepultura eclesiástica a Calletano Fallas, adulto, casado con Felipa Mora; fallecio de calentura, en edad de cuarenta y tres años; y se confeso; y no recibió los demas sacramentos por estar enteramente demente y el del viatico por estar con vomito; y lo firmo Rafael B. de J. Chinchilla, rubricado" (ABAT. LDA, N², f. 28, a. 11).

\section{DEMENCIA}

Pese a que lo que hoy conocemos como demencia (a veces citada como locura) no es exactamente lo mismo que hace dos siglos, las referencias sobre este padecimiento, algunas veces pasajero, otras permanente y otras tantas ficticio, se hallan en diversos documentos coloniales custodiados en el ANCR.

Por eso, en los estudios sobre enfermedades mentales, los siguientes casos podrían algún día ser importantes:

En Cartago, el 28 de julio de 1750, José Manuel Carranza, vecino de Cartago, hijo legítimo de José Antonio Carranza -hermano laico de la orden franciscana- y doña Nicolasa de Aguilar [o Morales], pide ser declarado capaz de administrar sus bienes. José Antonio asegura:

"que habiendo fallecido mi madre y hallarse mi padre demente, por lo que vuestra merced se halla estudiando en la causa mortual de la dicha mi madre" (ANCR. CC. №4360).
En otro caso anterior, en noviembre de 1730, el capitán don José Lebrón reclama el pago que hizo a don Pantaleón de la Pedroza por la curación del alférez Francisco de Loría, esposo de Angela de Chavarría.

Al respecto, el sacerdote don Francisco de Ocampo Golfín afirma:

"El alférez Francisco Loría, vecino de esta ciudad y morador en los valles de Barva, adoleciendo de diferentes achaques y principalmente en la cabeza demente a lo que parecía, como que le tenían amarrado con una cadena" (ANCR. CC. $\mathrm{N}^{\circ} 4268$, f.5).

Un caso singular es el de los medio hermanos Ramón Ulate y José Manuel Segura, hijos de doña Antonia Josefa de Saborío (el primero habido con el Cap. Francisco de Ulate y el segundo con el Cap. José Francisco de Segura). Ambos fueron declarados sucesivamente "dementes", y don Miguel y don Trinidad Herrera, también medio hermanos de los enfermos, debieron asegurar los bienes que 
poseían mientras estuvieran en esa condición (Fig. 1 y Apéndice $\mathrm{N}^{\circ} 3$ ).

Por supuesto, en aquella época como hoy, se podía justificar un comportamiento inadecuado alegando locura pasajera, y aun el alcoholismo consetudinario podía ser un fuerte motivo para catalogar a alguien como demente y en otras se convertía en una buena excusa para evitar algún castigo.

En San José, en 1814, Manuela Vargas, esposa de José Antonio Monge, alega que, "hallándose mi marido quasi demente y en la actualidad arrestado en dicha población de orden del alcalde don Romualdo Saborío, por no haber satisfecho las costas de una sumaria que injustamente se instruyó", no se le nombró defensor (ANCR. CC. $\mathrm{N}^{\circ} 2580$ ).

Monge fue acusado en mayo del citado año por don José Ana Jiménez, regidor de San José, porque "tuvo la osadía y atrevimiento" de romper el cerco y poner una "tranquera" que dejaba abierta, por donde podían salirse más de 280 bestias caballares y vacunas que tenía en el lugar, "con cuyo hecho ha cometido el delito

\section{Figura $\mathrm{N}^{\circ} 1$}

Descendientes de Da, Antonia Jasefa Saborio

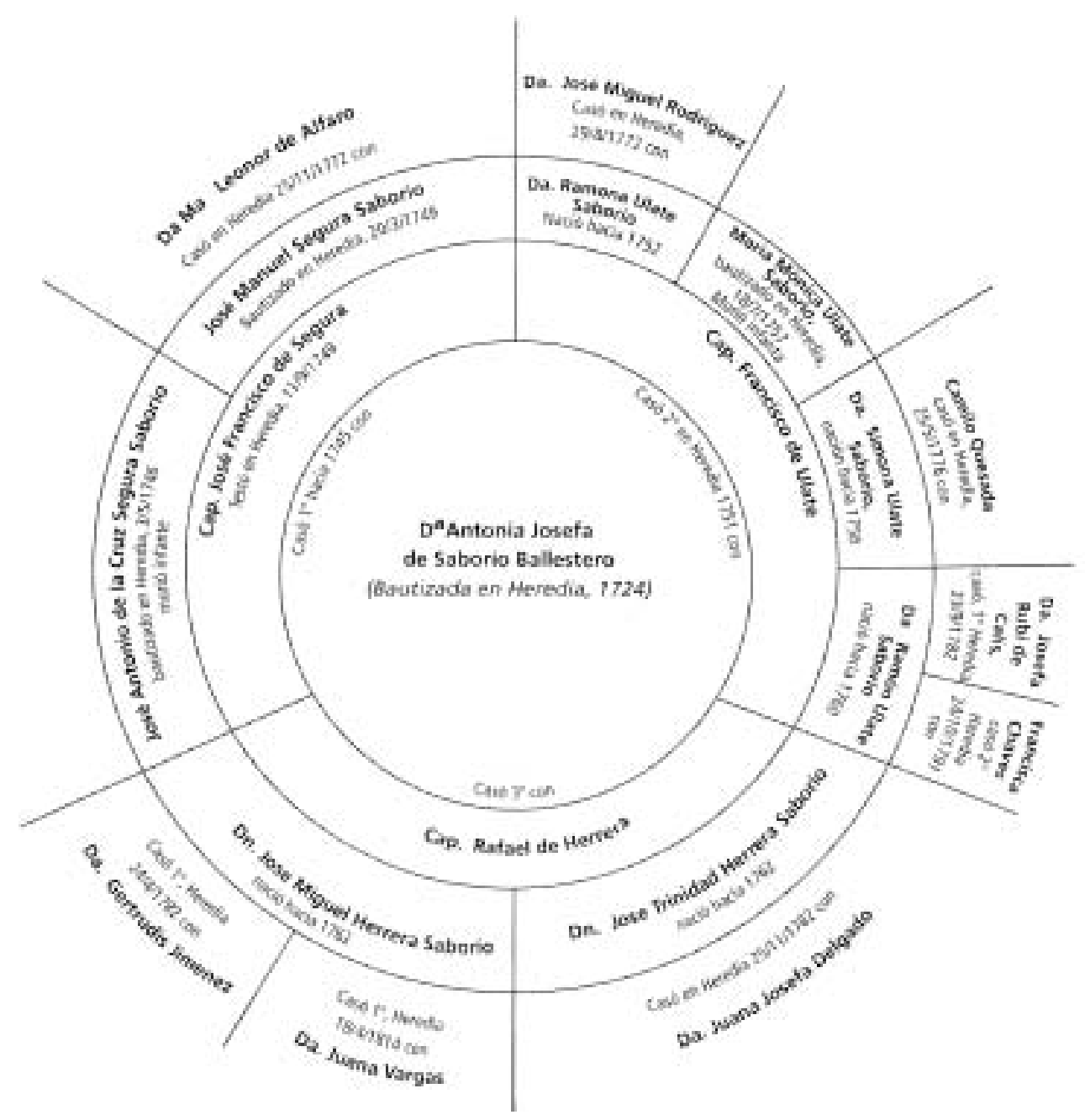


de insultar mi persona y quebrantar con escándalo el séptimo precepto del Decálogo, que prohíbe hacer daño injusto al prójimo".

Jiménez añadía que además de haberle robado una vaca, José Antonio Monge "está conocido en esta ciudad y sus barrios por hombre vago, sin oficio y continuamente ebrio en las calles, plazas y tabernas, y que por este vicio no tiene paz con sus vecinos ni con sus mismos hermanos pues con ellos ha tenido riñas y les ha tirado de machetazos (...) [que es] hombre rústico, malcriado y tan insolente y de genio altanero que delante de usted mismo [don Gregorio de Ulloa, alcalde primero de San José] desafió a su hermano mayor, nombrado José Manuel Monge, faltando con escándalo al respeto que se debe a la Real Justicia”.

Después de múltiples trámites legales y el pronunciamiento del abogado de la Real Audiencia de Guatemala, Monge es absuelto de los cargos y condenado a pagar las costas judiciales. No queda claro si efectivamente Monge fue considerado demente por las autoridades o simplemente como bebedor habitual.

Sobre alegatos de locura pasajera, destaca la del Lic. Dn. Rafael Barroeta, vocal de la Justa Superior Gubernativa de Costa Rica, quien afirma "que la noche del veinte y quatro del corriente [febrero de 1823] fue acometido de una locura que me duro solo veintiquatro horas pues amaneci bueno el veintiseis, necesito de retirarme y partarme [sic] de todos mis negocios y asi suplico a Vuestra Excelencia me exima el cargo de vocal de esta Excelentisima Junta” y que no lo hagan al menos un año. La Junta lo eximió del desempeño del cargo pero ignoramos si Barroeta siguió sufriendo de ataques de locura de un día (ANCR. PI. $\mathrm{N}^{\circ} 735$ ).

\section{LA CONSANGUINIDAD}

La consanguinidad es otra de las áreas en que la genealogía tiene mucho que aportar pues nuestro país se caracterizó de manera general hasta mediados del siglo XX por frecuentes matrimonios consanguíneos (esta es una apreciación personal basada en casi dos décadas de experiencia en investigación de familias de todo el Valle Central); por supuesto, no escapa ninguna localidad, pero sobresalen lugares como Desamparados, Alajuelita, Santa María de Dota, San Joaquín de Flores, Santo Domingo, Poás y San Antonio de Belén.

Mi apreciación empírica se comprueba plenamente en el trabajo de Ana Lorena Zumbado (1989) cuyos resultados mostraron que los niveles generales de consanguinidad en el país estaban decreciendo en el tiempo (las fechas extremas del periodo que investigó fueron 1840 y 1969).

Las pesquisas en esta área son fundamentales en campos como la genética humana, la medicina y las ciencias sociales (Zumbado 1989); destacan trabajos como los de Ramiro Barrantes en la parroquia de Santa María de Dota (1985) y la misma Zumbado en diversas parroquias del Valle Central (ver Morera y Barrantes 2004).

Los estudios de consanguinidad se sustentan en las series de matrimonios de las distintas parroquias; sin embargo, si se desea profundizar se deben considerar los expedientes matrimoniales pues estos brindan muchos más datos acerca de la pareja, de su realidad familiar y social.

Gracias a que las leyes canónicas de la Iglesia Católica establecían una serie de impedimentos para el matrimonio, entre los que estaba el parentesco, hoy contamos con la serie de expedientes matrimoniales que incluían las dispensas de parentesco -que podían ser de consanguinidad, de afinidad o de compadrazgo- y que es siempre una de las series más voluminosas de los archivos eclesiásticos (Segura y Ryskamp 1996).

Los impedimentos de consanguinidad se refieren a los parentescos de los contrayentes, o novios, y se valoran según el grado en que se encuentran ambos respecto de un antepasado común (o pareja de antepasados). De esta manera, si se comparte un abuelo, el parentesco es de segundo grado igual; si un bisabuelo, es de tercer grado igual, y si es un tatarabuelo, es de cuarto grado igual (ver Fig. 7); se dice que el 
grado es igual porque ambos contrayentes están en el mismo grado respecto del antepasado común. Sin embargo, a menudo el grado no es el mismo para ambos; por ejemplo, uno de los tatarabuelos del novio y uno de los bisabuelos de la novia es la misma persona, en este caso el parentesco es de tercer con cuarto grado desigual (ver Fig. 5). También se citan en los documentos si es línea directa (si ambos vienen de una misma línea agnática, o de varón) o línea colateral o transversal (si el parentesco se presenta por otras líneas).

Por su parte, los impedimentos de afinidad se dan cuando uno de los contrayentes es pariente de cónyuge difunto del otro contrayente (afinidad lícita; ver Fig. 5), o de un antiguo amante de ese otro contrayente (afinidad ilícita; ver Fig. 6). Los grados de parentesco se miden de la misma manera descrita en el párrafo anterior, pero estos incluirán al contrayente que es pariente del cónyuge difunto y a este (lícita) o al contrayente que es pariente del antiguo amante y a este (ilícita). Por último, la dispensa por parentesco espiritual, o compadrazgo, históricamente ha sido poco frecuente en Costa Rica; se daba cuando uno de los contrayentes había sido padrino en alguno de los sacramentos del otro contrayente.

El siguiente ejemplo se refiere a un caso extremo en cuanto a número de impedimentos $(n=6)$, pero relativamente frecuente en la parroquia de Poás de Alajuela, donde muchos compartían las ascendencias por los apellidos Herrera y Murillo.

En Poás, provincia de Alajuela, el 13 de agosto de 1888, José Angel Herrera Murillo, de 26 años, y Mercedes Murillo Murillo, de 19, piden dispensa de seis impedimentos de consanguinidad que los unen (Fig. 2). (ABAT. FA. Caja N³77, Exp. 45).

Por supuesto, en el caso de estudios que abarcan extensos periodos de tiempo puede resultar difícil, si no imposible, confirmar cada uno de los parentescos que se citan en el expediente, pero algunas veces se omiten impedimentos (por desconocimiento de los contrayentes o para evitar pagos adicionales -recuérdese que la Iglesia Católica cobraba por levantar tales impedimentos-).

En Grecia, provincia de Alajuela, el 21 de enero de 1893, José Rojas Murillo, de 21 años, e Isolina Rojas Rojas, piden dispensa de tres

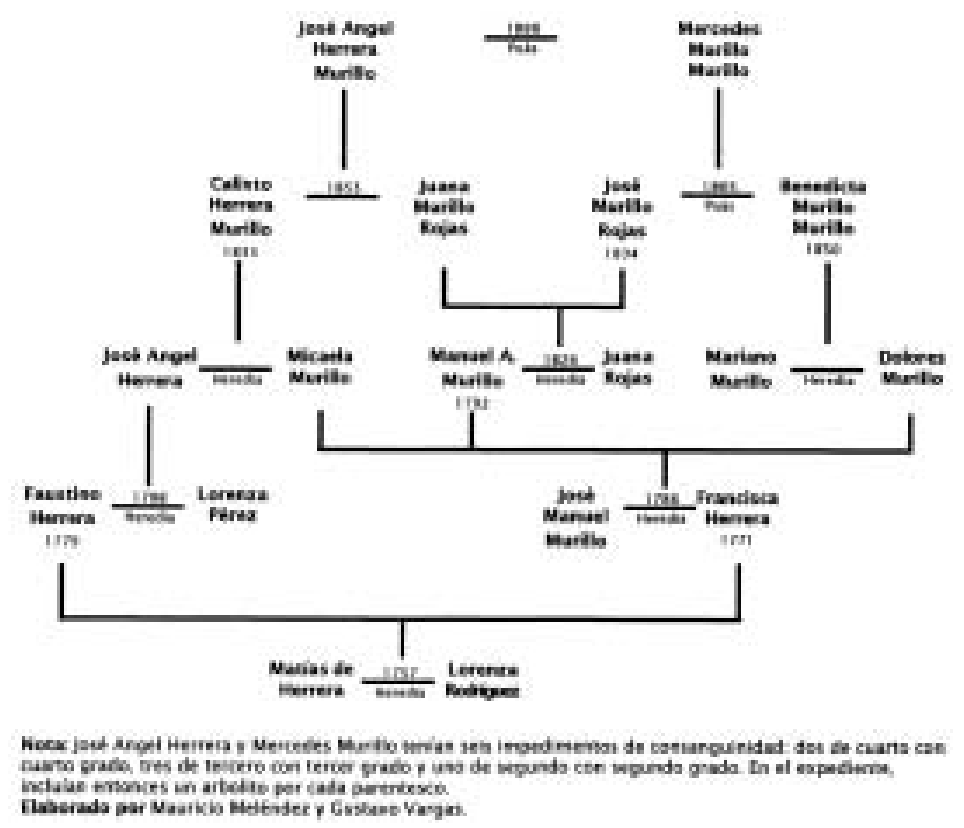

Fig. 2. Consanguinidad de José Angel Herrera Murillo y Mercedes Murillo Murillo (San Pedro de Poás, Alajuela, agosto de 1888). 
impedimentos de consanguinidad que los unen, pero dejaron de citar dos más y que no fueron consignados por los novios. (Fig. 3). (ABAT. CM. EM. Caja N60, Exp. 34).

En otras oportunidades, aunque los contrayentes saben que son parientes, ignoran la exactitud del parentesco. Por ejemplo, en San José, el 6 de abril de 1857, Francisco Meléndez Campos y Rafaela Zúniga Barboza solicitan dispensa para contraer matrimonio pues aseguran tener parentesco de tercer grado con cuarto grado, pues Rafael Meléndez había sido padre de Policarpo Meléndez y Felipa Meléndez; el primero fue padre de Andrés Meléndez, progenitor del novio; mientras la segunda había sido madre de Rafaela Castro, progenitora de Sebastián Zúñiga, padre de la novia. (ABAT. FA. Caja $N^{\circ}$ 112, Exp. 299).

En realidad, el parentesco era de cuarto con quinto grado, por lo que no había impedimento por esta línea, aunque sí lo tenían en tercer grado con tercero pues ambos contrayentes eran bisnietos de Pedro Campos (Fig. 4).

En otros casos, además de la consanguinidad se añadía el parentesco por afinidad (es decir, uno de los contrayentes era pariente del difunto cónyuge del otro). Por ejemplo, en Grecia, Alajuela, el 20 de abril de 1863, Jacinto Abarca Chacón, de 22 años, y Antonia Vargas Barrantes, de 25 años, piden dispensa de tres impedimentos, dos de consanguinidad y uno de afinidad; este último porque Jacinto Abarca Chacón era sobrino de Eugenio Chacón Barrantes, difunto esposo de Antonia Vargas Barrantes (Fig. 5) (ABAT. FA. Caja N 138, Exp. 101).

Por supuesto, los expedientes que involucran parentescos brindan información genealógica muy valiosa que, de otra manera, nunca se llegaría a conocer. El siguiente ejemplo permite vincular a un tronco común a dos mujeres, una de las cuales había mantenido relaciones sexuales con el novio, quien deseaba casar

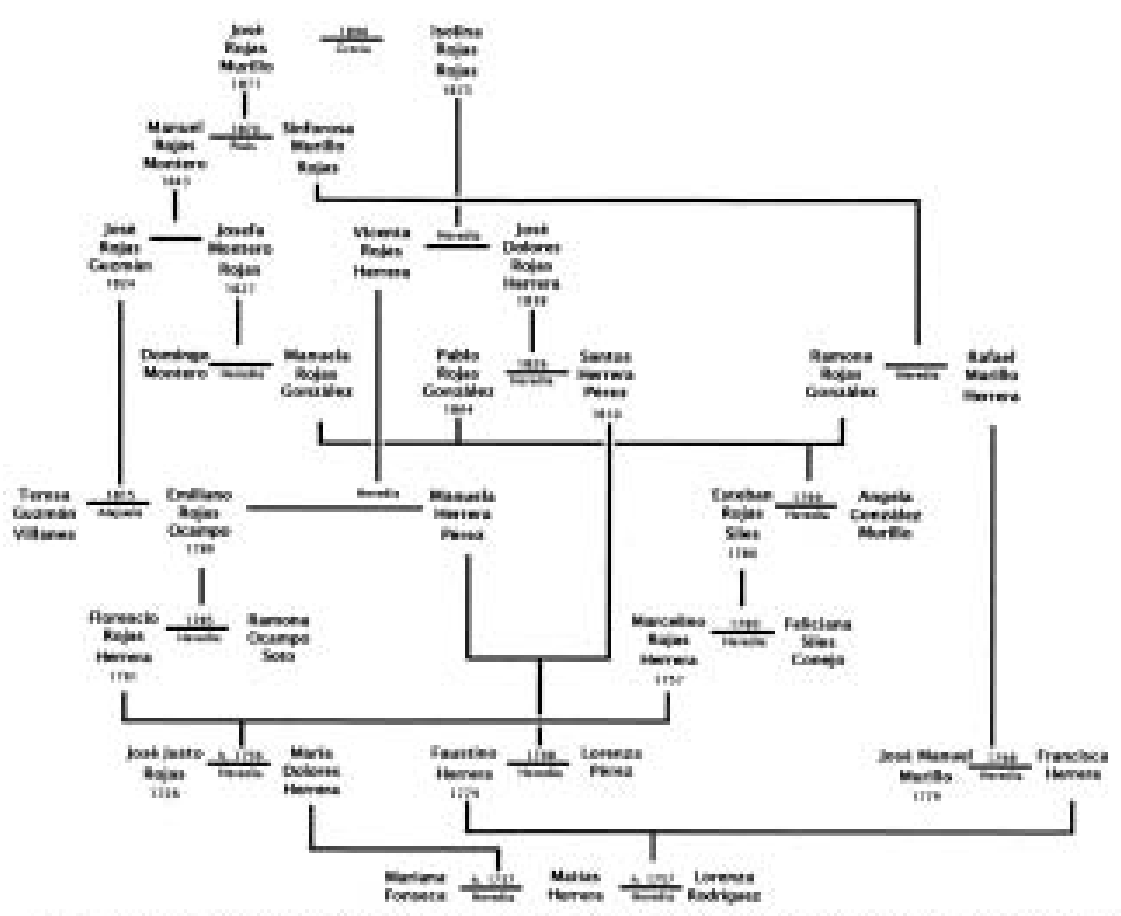

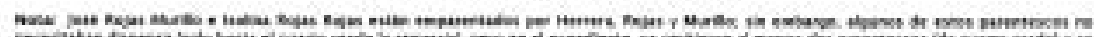

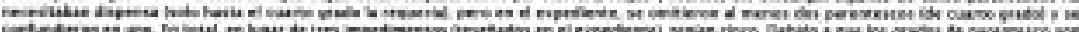

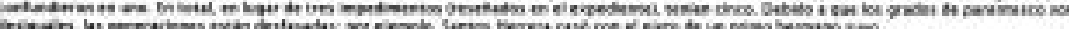

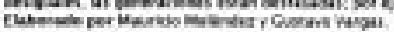

Fig. 3. Consanguinidad de José Rojas Murillo e Isolina Rojas Rojas. (Grecia, Alajuela, enero de 1893). 

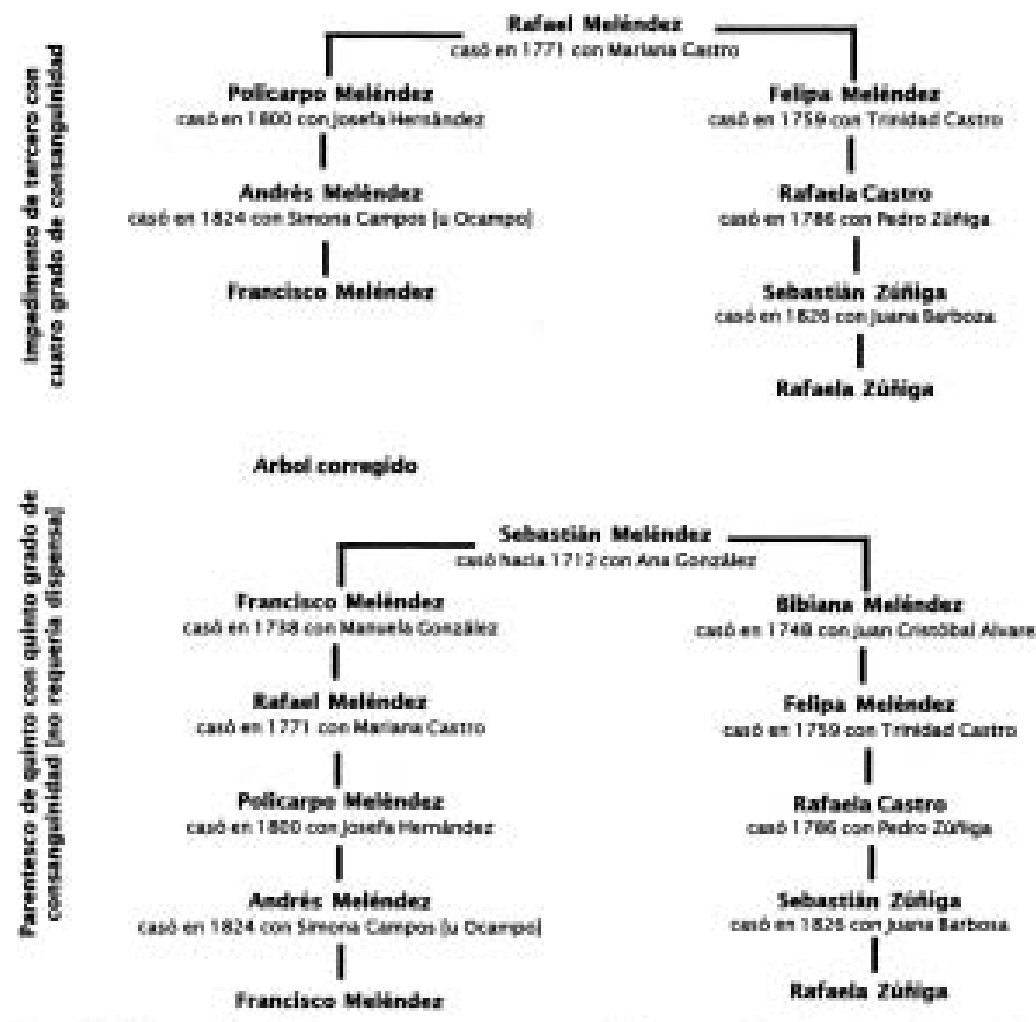

Nota: Debido a que ba arboles se reconstruven a partir de la memoria faniliar. la que despues de 100 alos puede no ser del sodo exacta. hallsmos casos coms ef anberior, es que efectivameme eran parientes por Meltndez, pero no tan cercanos como creian. Elaborado per Mauricio Melibidez.

Fig. 4. Consanguinidad de Francisco Meléndez Campos y Rafaela Zúñiga Barboza (San José, abril de 1857).

precisamente con una parienta de esa mujer (en esos casos se pide dispensa del impedimento de afinidad ilícita; es decir, producto de relaciones sexuales fuera de la ortodoxia matrimonial). En Cartago, el $1^{\circ}$ de agosto de 1854, José del Carmen Pérez, de 22 años, y María de Jesús Rivera, de 16 años, piden dispensa del impedimento de afinidad ilícita de cuarto grado (Fig. 6). (ABAT. CM. EM. Caja $\mathrm{N}^{\circ}$ 2, Exp. 55).

De la misma manera, en algunos expedientes matrimoniales se revelan filiaciones que no constan en la documentación oficial pues se trata de personas que fueron el resultado de relaciones fuera de la ortodoxia matrimonial (generalmente adulterio o sacrilegio -en este caso cuando se trataba de hijos de un sacerdote-); por ejemplo, José de la Cruz Céspedes casi siempre es citado como hijo legítimo de Juan Francisco Céspedes González y Mariana Ocampo Picado; asimismo, contrajo matrimonio con María Francisca Rodríguez Acosta, en cuya partida matrimonial (Heredia, 27 de noviembre de 1800) es consignado como hijo legítimo de los ya mencionados; sin embargo, ocasionalmente, él y sus hijos son consignados como Alfaro. La razón para el cambio de apellido eran totalmente desconocida pues no había Alfaro en sus ancestrías oficiales próximas. No obstante, gracias al expediente matrimonial de Gregorio Salas y Juliana Alfaro [también conocida como Juliana Céspedes], iniciado en Heredia, el 30 de setiembre de 1837 (AHDL. Expedientes Matrimoniales, Caja de los años 1836-1837), se pudo comprobar que José de la Cruz Céspedes había sido hijo de un primo 


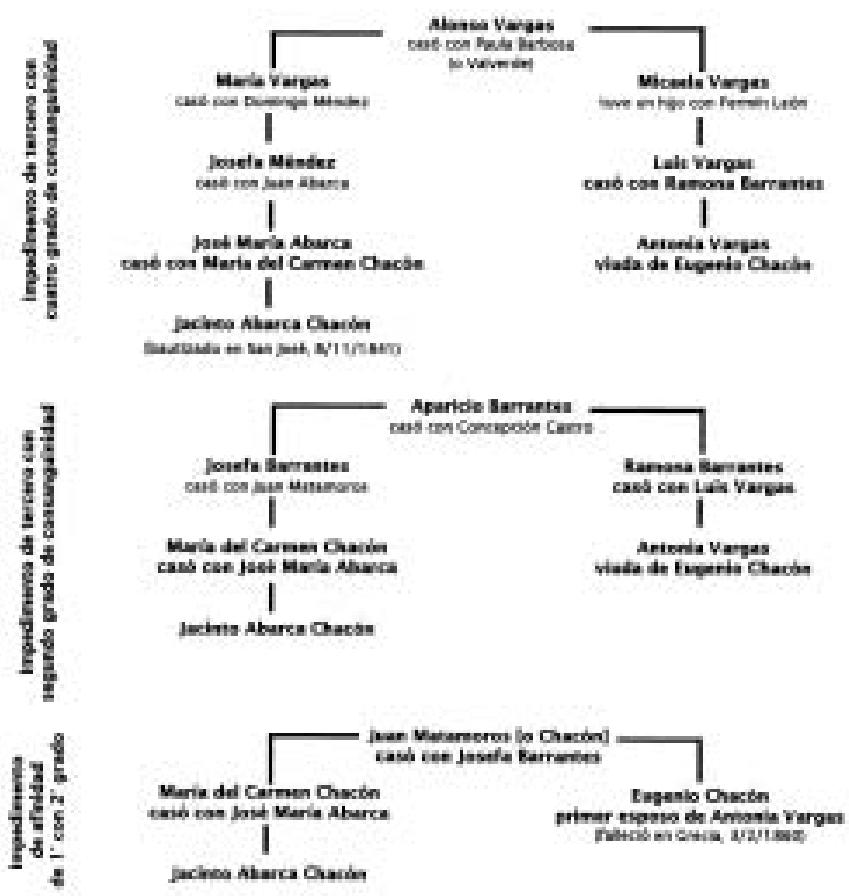

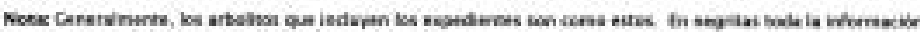

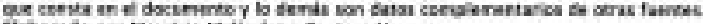

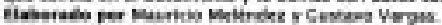

Fig. 5. Consanguinidad y afinidad de Jacinto Abarca Chacón y Antonia Vargas Barrantes. (Grecia, Alajuela, abril de 1863).

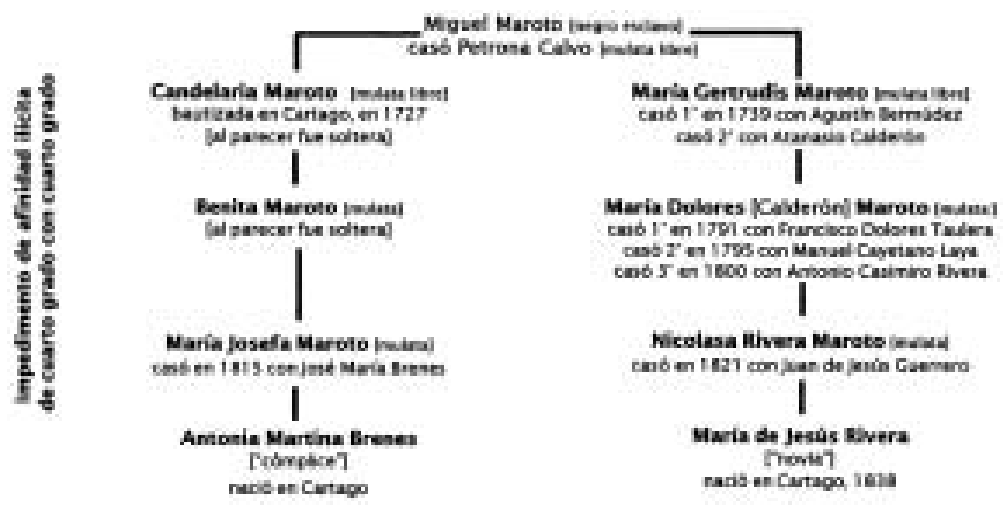

Note En nepritas la infornacibon que aparece en el expediente; lo demin a ha iomado de atras taentes

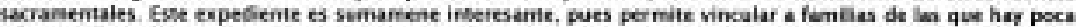
indermarion mis siendo madres solteras Randelaris Maroto madie de Befita Marvis, madre de Marie jasefo

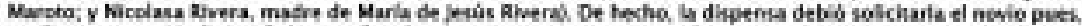
medanie carta, Macia jasefa Marats [matre de Aatnaia Martina Brenes] puse es alerta al cura sobe ba afiaidad

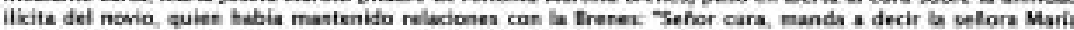

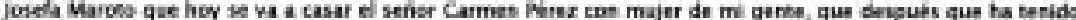
que hacer cen una y whora se va e casar cen etra de la mikma. y que se le avisa pera que disperse porque es que

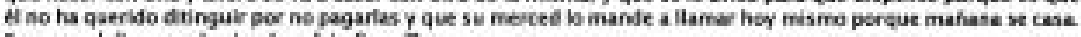
5 merced dispense la simpleas lsin firmar.

Claborado por Masricio Melendea.

Fig. 6. Afinidad entre José del Carmen Pérez y María de Jesús Rivera (Cartago, agosto de 1854). 
hermano del padre que se le asignaba oficialmente (ver Fig. 7); es decir, que su padre no había sido Juan Francisco Céspedes González sino Juan José Alfaro González. Debido a que Gregorio y Juliana resultaban ser parientes, piden dispensa para contraer matrimonio, la cual reciben desde León, el 19 de octubre del citado año, donde radicaba el Obispado de Nicaragua y Costa Rica. Tras la creación del Registro Civil (1888), algunos optaron de manera definitiva por el apellido Céspedes y otros por Alfaro.

Finalmente, como dijimos antes, los expedientes matrimoniales brindan mucha información sobre los contrayentes, que una escueta partida matrimonial no suele citar. En San Rafael de Cartago (hoy San Rafael de Oreamuno), el 11 de enero de 1876, José del Espíritu Santo Soto, "sordomudo", "manifestándose con señas bastantes claras que se desea casar con María Joaquina Meoño”, "por medio de señas que le hizo a Santiago Ramírez, muy versado ya con él", pide dispensa pues era pariente de Concepción Ramírez, primer marido de la Meoño. (ABAT. FA. Caja $\mathrm{N}^{\circ}$ 179, Exp. 304).

\section{EL PROYECTO DE LONGEVIDAD INUSUAL}

A continuación, veamos el trabajo genealógico para un proyecto interdisciplinario, en que antropología, genética y genealogía se entrelazan. Este proyecto está a cargo de Lorena Madrigal y participan Henriette Raventós, Guido Barbujani, Ramiro Barrantes, Reinaldo Pereira, Ramón Villegas y Mauricio Meléndez.

Aunque el proyecto "La herencia de longevidad inusual: un estudio diacrónico" se empezó a gestar desde hace algún tiempo, se

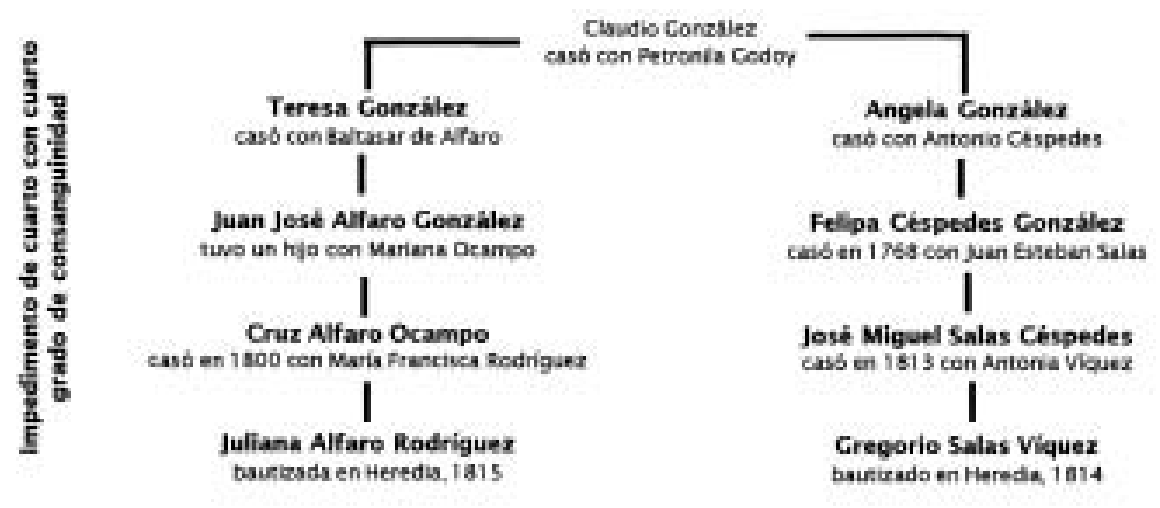

Arbol segùn la mayoría de las fuentes oficiales [pero no real]
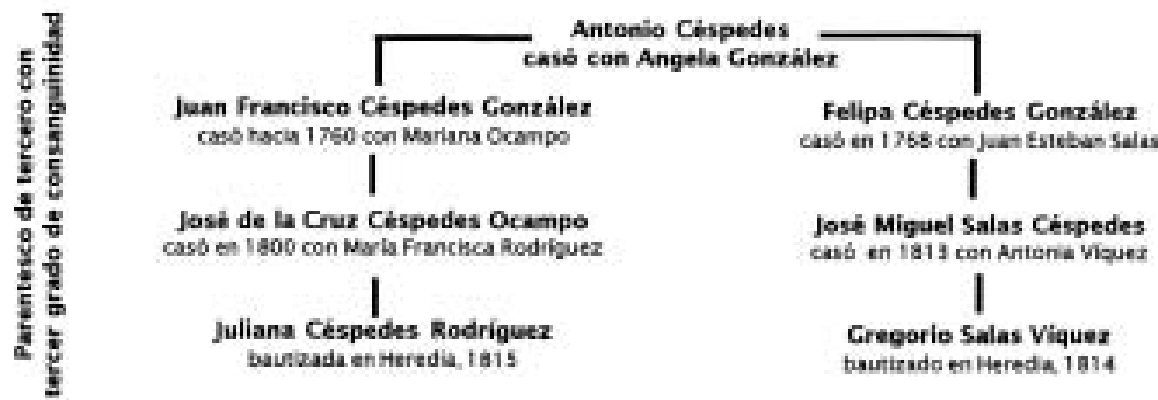

Fig. 7. Consanguinidad de Gregorio Salas Víquez y Juliana Alfaro Rodríguez (Heredia, setiembre-octubre de 1837). 
inició formalmente en enero del 2004. Es financiado por el Instituto Nacional de Salud de los Estados Unidos, por medio del Institute of Aging, y en él participan la Universidad del Sur de la Florida y la Universidad de Costa Rica.

Se pretende determinar si el material genético de los 150 atenienses participantes (personas nacidas en el cantón de Atenas, provincia de Alajuela, Costa Rica) se puede relacionar con la longevidad y si se puede comprobar la hipótesis de la abuela y el diferencial de supervivencia de su progenie (del área de la antropología).

La metodología y las fuentes de los estudios genealógicos que apoyan trabajos de otras disciplinas dependen en primera instancia de los objetivos del proyecto, en este caso por tratarse de la ascendencia matrilineal se rastrean exclusivamente las ancestrías maternas del participante y sus antepasadas.

Se parte de la información que brindaron los 150 participantes (todos de Atenas, Alajuela) en la entrevista inicial, cuya información básica se corrobora y amplía en el Registro Civil, posteriormente se completan las ascendencias con la consulta de las fuentes primarias del ABAT y el ANCR.

Gran parte de la información sacramental ya está procesada en la base de datos sobre Atenas y Palmares, perteneciente a Ramón Villegas, y luego se completan los vacíos (nacimiento, defunción, matrimonio y número de hijos) según el lugar de nacimiento o residencia de la antepasada que se investiga (es decir, aunque las primeras generaciones son atenienses, luego pasan a otras parroquias cercanas o a Alajuela, Heredia, San José y Cartago).

Cuando la información se refiere a Grecia, San Pedro de Poás, Sabanilla o Sarchí, todos en la provincia de Alajuela, se cuenta con la ayuda del ingeniero Gustavo Vargas Quesada, quien está procesando la información sacramental de estas parroquias; y cuando se refiere a Santo Domingo de Heredia, el administrador German Bolaños Zamora ha prestado también su colaboración. Además, han brindado su ayuda en diferentes etapas de la investigación Isidro Sánchez Vargas, Cecilia Lépiz Valls, Alicia
Palma Murillo, Dunia Leal Palma, Nora Virginia Arguedas Sibaja y Henry Rojas Esquivel.

Eventualmente, luego de este proceso, es posible que aún queden vacíos difíciles de llenar pues algunas veces los registros sacramentales (bautizos, matrimonios o defunciones) ya no existen o no fueron anotados en su momento; también puede deberse a que la partida que se busca está en una parroquia de la que no se tiene idea o no hay indicios para investigar en ella (esto ocurre sobre todo cuando hay movimientos migratorios simultáneos provenientes de distintas parroquias).

En todo caso, se intentará, para cada uno de los 150 casos, completar la información requerida (nacimiento, defunción y número de hijos) e, idealmente, se obtendrá una genealogía ascendente matrilineal exclusiva como la de la figura 8 , perteneciente a uno de los participantes, quien dio su autorización para reproducirla. En este caso, la ascendencia matrilineal se remonta hasta el momento mismo de la conquista del territorio costarricense; no obstante, esto es excepcional. En una primera etapa, las genealogías se han completado exhaustivamente desde fines del siglo XVIII al presente. Finalmente, mediante el análisis del ADN mitocondrial se intentará relacionar la longevidad con algún gen o grupo de genes específicos.

\section{PERSPECTIVAS}

Los registros genealógicos disponibles en Costa Rica permiten agrupar pacientes con una enfermedad particular en grandes familias extendidas, que algunas veces comprenden cientos de individuos por más de quince generaciones. La profundidad y comprehensibidad de los recursos genealógicos de Costa Rica perfectamente podrían rivalizar con los de Islandia (deCODE 2004), y son difíciles de encontrar en otras partes del mundo.

La pasión tradicional y académico-científica costarricense por construir árboles genealógicos confiere la capacidad de rastrear 


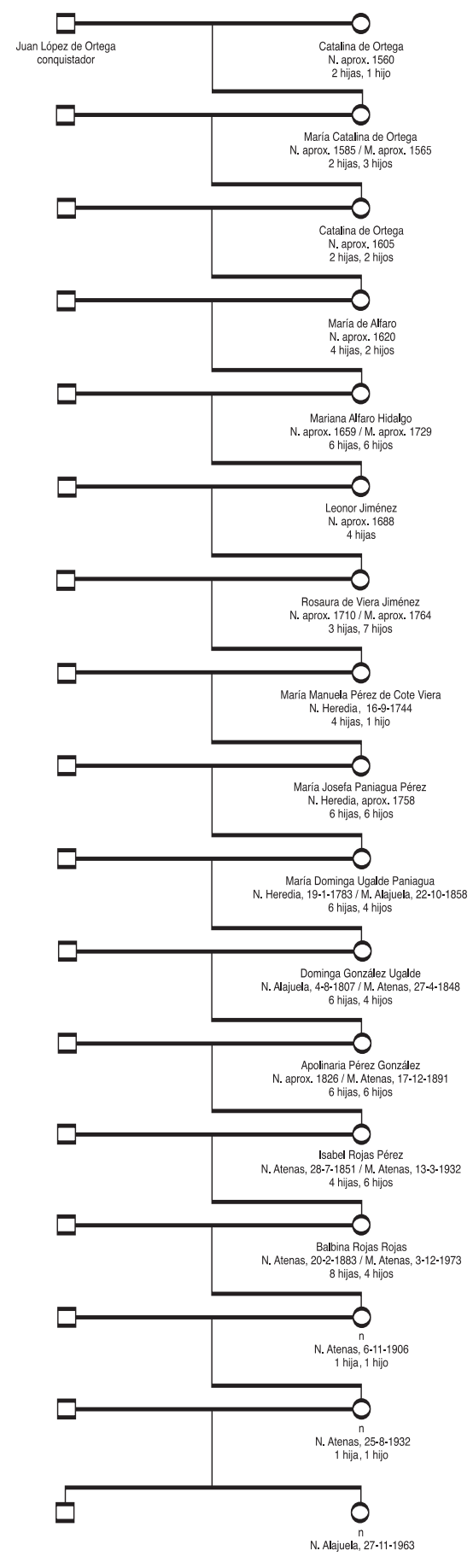

Fig. 8. Ascendencia matrilineal de uno de los casos investigados. el paso hereditario de muchos genes de enfermedades desde cientos de años atrás, en forma semejante a como se está realizando en forma intensiva y extensiva dicha población. Esto es importante ya que una población con los tres conjuntos de datos, genéticos, enfermedad y genealógicos es un recurso escaso en genética humana.

Actualmente se tienen grandes expectativas de que la comparación de los genotipos de individuos afectados con una enfermedad, emparentados cercana y lejanamente, pueda permitir identificar genes específicos y mutaciones involucradas causalmente o ligados a una enfermedad de herencia simple o compleja, en forma más eficientemente de lo que sería si solo se estudiaran pacientes no relacionados, y en poblaciones amplias. Es en este sentido en que Costa Rica muestra sus ventajas potenciales para los estudios genéticos -fuertemente apoyados por la genealogía- de cara a la búsqueda de respuestas a algunas de las interrogantes más candentes de la biomedicina actual, y a la comprensión de la historia evolutiva de su población.

\section{RESUMEN}

El amplio desarrollo de los estudios genealógicos basados en la documentación custodiada en los archivos históricos ha representado un fuerte apoyo a la investigación genética en Costa Rica durante el último cuarto de siglo y como resultado de tal interacción se han podido responder algunas interrogantes sobre la historia poblacional, sobre varias enfermedades hereditarias y ha dejado vislumbrar la de otras; asimismo, deja entrever enormes ventajas pontenciales de la población costarricense como modelo para los estudios genéticos.

\section{REFERENCIAS}

ANCR-ASOGEHI. 2000. Curso de Introducción a la Genealogía (materiales del curso, mimiografiado). Archivo Nacional de Costa Rica-Asociación de Genealogía e Historia de Costa Rica. San Jose, Costa Rica.

Barrantes, R. 1985. Estructura poblacional y consanguinidad en Dota, Costa Rica, 1888-1962. Rev. Biol. Trop. 26: 347-357. 
Barrantes, R. \& B. Morera. 1999. Contribución del genoma amerindio en la formacion de la poblacion costarricense. Vínculos 24: 85-93.

Morera, B. \& R. Barrantes. 2004. Is the Central Valley of Costa Rica a genetic isolate? Rev. Biol. Trop. 52: XIX-XXX.

Chacón de Umaña, L.A. 2000. Archivo Nacional de Costa Rica. Rev. Acad. Cost. Cien. Genealógicas (Costa Rica). 37: 243-248.

Escamilla, M.A., M. Spesny, V.I. Reus, A. Gallegos, L. Meza, J. Molina, L. Sandkuijl, E. Fournier, P. León, L. Smith \& N. Freimer. 1996. Use of linkage disequilibrium approaches to map genes for bipolar disorder in the Costa Rican population. Am. J. Med. Genet. 67: 244-253.

Fernández, L. 1883. Colección de documentos para la historia de Costa Rica. Tomo III. Imprenta Nacional. San José, Costa Rica. pp. 53.

Fernández, L. 1907. Colección de documentos para la historia de Costa Rica. Tomo VII. Imprenta Viuda de Luis Tasso. Barcelona, España.

Freimer, N.B., V.I. Reus, M. Escamilla, M Spesny, L. Smith, S. Service, A. Gallegos, L. Meza, S. Batki, S. Vinogradov, P. León \& L.A. Sandkujil. 1996. An approache to investigating linkage for bipolar disorder using large Costa Rican pedigrees. Am. J. Med. Genet. 67: 254-263.

Fournier, E. \& M. Vega, M. sin fecha. Inventario de los microfilms que se encuentran en el Archivo de la Curia Metropolitana de San José y que contienen las series de bautizos, confirmas, matrimonios y defunciones de las parroquias costarricenses. Archivo Eclesiástico de la Curia Metropolitana. San José, Costa Rica.

Gagini, C. (ed.). 1921. Documentos para la historia de Costa Rica. Tomo I. Imprenta Nacional. San José, Costa Rica.

Galbis Díez, M. del C. 1986. Catálogo de pasajeros a Indias. Volumen VI. 1578-1585. Ministerio de Cultura. Murcia, España.

Gudmundson, L. 1978. Mecanismos de movilidad social para la población de procedencia africana en Costa Rica colonial: manumisión y mestizaje. In L. Gudmundson. Estratificación socio-racial y económica de Costa Rica: 1700-1850. EUNED, San José. p. 14.

IJSUD. sin fecha. Guía para realizar la investigación genealógica. Iglesia de Jesucristo de los Santos de los Ultimos Días. Guatemala.
Jacobus, D.L. 1996. Genealogy as Pastime and Profession. Second Edition. Genealogical Publishing Co., Baltimore, Maryland.

León, P. \& E. Fournier. 2000. Impacto de la genealogía en los estudios genéticos. Revista de la Academia Cost. Cienc. Genealogicas 38: 127-137.

León, P., H. Raventós, E. Lynch, J. Morrow \& MC. King. 1992. A gene for an hinherited form of deafness maps to chromosome 5q31. Proc. Nat. Acad. Sci. USA 89: 5181-5184.

León, P., R. Vanegas, J.R. Sánchez, J.A. Bonilla, J. Brenes, A.L. Howell, L. Torres, R. Fernández \& J. Mainieri. 1981. Caracterización de una sordera hereditaria de transmisión dominante, autosómica y de expresión tardía. Acta Méd. Cost. (Costa Rica). 24: 51-58.

Lynch, E.D., M.K. Lee, J.E. Morrow, P.L. Welcsh, P.E. León \& M.-C. King. 1997. Nonsyndromic deafness DFNA 1 associated with mutation of a human homo$\log$ of the Drosophila gene diaphanus. Science 278: 1315-1318.

Madrigal, L. 1999. The Grandmother hypothesis and the differential survival of mtDNA lineages in the small human population. Proyect description. University of South Florida, U.S.A.

Madrigal, L., B. Ware, R. Miller, G. Sáenz, M. Chavez \& D. Dykes. 2001. Ethnicity, gene flow, and population subdivision in Limon, Costa Rica. Am. J. Phys. Anthrop. 114: 99-108.

Martínez Peláez, S. 1998. La patria del criollo, ensayo de interpretación de la realidad colonial guatemalteca. Fondo de Cultura Económica. México.

Meléndez Chaverri, C. 1972. Juan Vásquez de Coronado. Editorial Costa Rica. San José, Costa Rica.

Meléndez Chaverri, C. 1977. Costa Rica, tierra y poblamiento en la Colonia. Editorial Costa Rica. San José, Costa Rica.

Meléndez Chaverri, C. 1982. Conquistadores y pobladores: orígenes histórico-sociales de los costarricenses. Editorial de la Universidad Estatal a Distancia. San José, Costa Rica.

Meléndez Chaverri, C. \& Q. Duncan. 1989. El Negro en Costa Rica. Editorial Costa Rica, San José, Costa Rica. p. 58-82.

Meléndez Obando, M.O. 1993. Dominga Fallas. Un siglo de engaños. In T. Lobo. (ed.). Entre Dios y el diablo. Editorial Universidad de Costa Rica, San José, Costa Rica. p. 115-148. 
Meléndez Obando, M.O. 1994. El Archivo Eclesiástico de la Curia Metropolitana. Custodio de nuestra historia. La Prensa Libre. San José, Costa Rica. (15 de febrero): 13 .

Meléndez Obando, M.O. 1997. Las familias. In T. Lobo Wiehoff \& M. Meléndez-Obando (eds.). Negros y blancos, todo mezclado. Editorial de la Universidad de Costa Rica. San José, Costa Rica. p. 81-214.

Meléndez Obando, M.O. 1999. Genes reveladores. El Financiero. San José, Costa Rica. (15-21 de marzo): 34.

Meléndez Obando, M.O. 2000. La genealogía iberoamericana en tiempos de globalización. Rev. Acad. Cost. Cien. Genealógicas (Costa Rica). 38: 351-361.

Meléndez Obando, M.O. 2003. Estratificación sociorracial y matrimonio en la Intendencia de San Salvador y la Alcadía Mayor de Sonsonate. In A.M. Gómez \& S.A. Herrera (compiladores). Mestizaje, poder y sociedad. Ensayos de la historia colonial de las provincias de San Salvador y Sonsonate. FLACSO. San Salvador, El Salvador. p. 47-69.

Morera, B. \& R. Barrantes. 1995. Genes e historia: el mestizaje en Costa Rica. Rev. Historia (Costa Rica). 32: 43-64.

Morera, B., R. Marín-Rojas \& R. Barrantes. 2001. Análisis de varios marcadores genéticos clásicos en la población de Costa Rica. Rev. Biol. Trop. 49: 1237-1252.

Morera, B., R. Barrantes \& R. Marín. 2003. Gene Admixture in the Costa Rican Population. Ann. Hum. Genet. 67: 71-80.

Morera, B., R. Villegas Palma, F. Calafell, D. Comas, M.O. Meléndez Obando \& J. Bertranpetit. 2004. Combined genealogical and mtDNA analysis for the characterisation of early Colonial historic female lineages in Costa Rica. Rev. Biol. Trop. 52: en prensa.

Peralta, M.M. 1883. Costa Rica, Nicaragua y Panamá en el siglo XVI. Su historia y sus límites. Librería de M. Murillo. Madrid, España.

Quirós, C. 1990. La era de la encomienda. Editorial de la Universidad de Costa Rica. San José, Costa Rica.

Sáenz, G.F., G. Arroyo, M.A. Alvarado, G. Montero, J. Jiménez \& E. Valenciano. 1974. Hemoglobinas anormales en una población estudiantil universitaria. Rev. Biol. Trop. 21: 417-424.

Sáenz, G.F., J. Elizondo, G. Arroyo, J. Valenciano, L.F. Rojas, J. Jiménez, G. Montero \& J.E. Sánchez. 1980.
Hemoglobinopatías en 12.000 escolares. Acta Méd. Cost. 23: 89-99.

Sampedro, J.L. 1999. Con nombre y apellido. Cómo localizar a nuestros antepasados. Ediciones Martínez Roca. Barcelona, España.

Sanabria Martínez, V.M. 1957. Genealogías de Cartago hasta 1850. VI tomos. San José, Costa Rica.

Sánchez Ochoa, P. 1976. Los hidalgos de Guatemala, realidad y apariencia en un sistema de valores. Publicaciones de Universidad de Sevilla. Jerez de la Frontera, Cádiz.

\section{REFERENCIAS DE INTERNET}

deCODE. 2004. deCODE genetics. (Consultado 16 de junio, 2004. http://www.decode.com).

\section{ABREVIATURAS}

a: asiento.

ABAT: Archivo Histórico Arquidiocesano Bernardo Augusto Thiel (antes Archivo Eclesiástico de la Curia Metropolitana).

AGN: Archivo General de la Nación (México)

ANCR: Archivo Nacional de Costa Rica.

AHDL: Archivo Histórico Diocesano de León (Nicaragua).

CC: Complementario Colonial.

Exp.: expediente.

f.: folio.

LBH: Libro de Bautizos de Heredia.

LDA: Libro de Defunciones de Aserrí.

LDC: Libro de Defunciones de Cartago.

LDSDH: Libro de Defunciones de Santo Domingo de Heredia.

LMC: Libro de Matrimonios de Cartago.

LMSJ: Libro de Matrimonios de San José.

$\mathrm{N}^{\circ}$ : número.

PI: Provincial Independiente.

s.: sin.

v.: vuelto.

Vol.: volumen. 


\section{APÉNDICE 1}

\section{Conquistadores y pobladores (1561-1599)}

\section{Conquistador o poblador}

1. Alvaro de Acuña (1535) esp VC

2. Pero Afán de Ribera* (1492) esp

3. Diego de Aguilar (1548) VR

4. Hernando de Aguilar (1545) ART

5. Pero Alonso de las Alas (1536) C

6. Cristóbal de Alfaro (1540) $\mathbf{P}$

7. Juan Alonso** (1534) C

8. Antonio Alvarez Pereira (1530) por $\mathbf{C}$

9. Francisco de Arrieta (1575) F

10. Diego de Artieda Chirinos* esp

11. Juan Barbosa $\mathbf{C}$

12. Martín Beleño** $\mathbf{F}$

13. Román Benito (1530) C

14. Alonso de Bonilla (1556) nic VC

15. Francisco de Bonilla** VC

16. Ambrosio de Brenes (1569) F

17. Jerónimo Busto de Villegas C

18. Juan Cabral** ART?

19. Miguel Calvo esp F

20. Antonio de Carvajal VC

21. Diego del Casar Escalante $\mathbf{P}$

22. Luis Cascante de Rojas F

23. Ignacio Cota (1530) esp C

24. Alonso del Cubillo (1540) esp A

25. Cristóbal de Chaves (1569) F

26. Gaspar de Chinchilla (1540) F

27. Gaspar Delgado (1540) $\mathbf{P}$

28. Pedro Díaz de Loría (1538) VC

29. Luis Díaz de Trejo** $\mathbf{C}$

30. Pedro Enríquez de Cadórniga** esp $\mathbf{P}$

31. Francisco de Estrada** (1527) C

32. Luis de Esquivel Añasco $\mathbf{F}$

33. Alonso Fajardo** VC

34. Hernando Farfán C

35. Jerónimo Felipe (1568) esp F

36. Leandro de Figueroa (1566) esp F

37. Pedro de Flores (1554) A

38. Francisco de Fonseca VC

39. Juan García $\mathbf{P}$

40. Pedro García Carrasco (1542) VC

41. Francisco Ginovés [Ferreto] (1512) C

42. Alonso Gómez Macotela $\mathbf{F}$

43. Baltasar González (1532)** VC

44. Alonso de Guido (1543)

45. Alonso Gutiérrez de Sibaja (1541) gua C

46. Domingo Hernández (1536) C

47. Antonio Hernández Camelo VC

48. Antonio de Herrera** VC

49. Francisco Hidalgo** A

50. Alonso Jáimez esp $\mathbf{F}$

51. Diego Jáimez** $\mathbf{F}$
Esposa o "compañera"

Catalina de Acuña e

Da. Petronila de Paz e

Catalina Palacios e

María de Guido nic e hc

Catalina Gutiérrez Jaramillo e hc

Da. Inés [india]

Catalina Gómez e

María de Céspedes e

María Verdugo (Nicaragua) e

Juana Gómez e

Ana López de Ortega e hc

María de Espinosa e hc

Catalina Gutiérrez Jaramillo e hc

Mariana Chinchilla hond e

Da. Ana e

Juana Solano e he

Da. Isabel Ruiz de Villatoro esp e

María de Alfaro e hc

Catalina Palacios e hc

María del Castillo e hc

Magdalena Ojeda e

Antonia de Trujillo e y Catalina Rueda e nc María de Ortega e hc

Inés Solano e hc

Isabel Juárez e hc

Catalina Hernández e

Juana Carrillo e

Jerónima de Avila e

Isabel Núñez e

María Alvarez de Oviedo nic e

Inés Pérez e 
52. Gómez Jaramillo $\mathbf{P}$

53. Alonso Jiménez (1544) esp VC

54. Domingo Jiménez (1534) VR

55. Juan Jiménez esp VC

56. Francisco Lobo de Gamaza** (1534) VC

57. Fernando López de Azcuña $\mathbf{F}$

58. Juan López Cerrato de Sotomayor*** esp A

59. Juan López de Ortega (1546) $\mathbf{P}$

60. Sebastián López de Quesada $\mathbf{P}$

61. Cristóbal de Madrigal VC

62. Francisco Magariño VC

63. Pedro Luis Medina Cueto $\mathbf{F}$

64. Esteban de Mena (1532) C

65. Vicencio Milanés (1522)** it

66. Martín de Miranda** VC

67. Felipe Monge (1565) esp F

68. Morales F

69. Francisco de Ocampo Golfín (1570) esp F

70. Francisco Ochoa (1540) ART

71. Juan Ordóñez del Castillo (1535) C

72. Matías de Palacios (1550) P

73. Francisco Pavón** ART

74. Diego Peláez de Berríos (1565) F

75. Juan de Peñaranda (1535) esp ART

76. Antonio de Peralta esp VC

77. Gaspar Pereira Cardoso (1570) por F

78. Juan Pereira VC?

79. Juan Pérez (1522) F

80. Alonso Pérez Farfán (1527) esp C

81. Pedro de la Portilla (1547) A

82. Agustín Félix de Prendas** (1558) ART

83. Diego de Quesada (1552) esp ART

84. Diego Quintero** C

85. Francisco Ramiro Corajo $\mathbf{P}$

86. Jerónimo de Retes (1560) esp F

87. Pedro de Ribero y Escobar (1538) VC

88. Nicolás Rodas (1567)** $\mathbf{F}$

89. Francisco Rodríguez** $\mathbf{P}$

90. Gaspar Rodríguez (1550) A

91. Juan Rodríguez Calderón** (1550) $\mathbf{P}$

92. Diego Rodríguez Chacón VC

93. Domingo Rodríguez Portugués $\mathbf{F}$

94. Bartolomé Sánchez (1555) $\mathbf{P}$

95. Miguel Sánchez de Guido (1528) esp C

96. Juan Solano (1538) esp C

97. Juan Suazo ${ }^{1}$

98. Salvador de Torres (1576) esp F

99. Diego de Trejo** (1538) C

100. Jerónimo Vanegas (1551) mex VR

101. Blas de Vera Bustamente** VC

102. Diego de Zúñiga $\mathbf{F}$

\author{
Magdalena Gutiérrez e \\ Gracia [india] \\ Catalina de Ortega e y María López [india] \\ Elvira Gómez e \\ Isabel de Carvajal e hc
}

Inés Hidalgo e

Francisca López e he nc

Inés de Benavides e hc y Catalina Tuia [india]

Luisa Hernández e hc

¿Da. Inés de Ampuero e?, Da. Juana Chacón e

Da. Andrea Vásquez de Coronado e nc

Sabina de Artieda esp e

Juana del Moral e

Isabel de Acuña e hc

Francisca de Avila e Inés [india]

Marina de Anangas esp [no vino a CR]

Ana Gómez e hc

Beatriz Fernández y Da. Tomasina de Lerma

Francisca Gutiérrez de Sibaja mst e hc

Francisca de Zúñiga e

María de Ortega e hc

Catalina de Vega e

Inés Rodríguez e y María Ramírez e

Da. Inés Alvarez Pereira mst e hc

Leonor de Mendoza e hc

Da. Mayor de Benavides esp e

Isabel Rodríguez e

Inés Pérez Farfán e hc

Teresa Fernández [no vino a CR] e
Nota: Se consideran aquí fundadores aquellos que ingresaron antes de 1599 y dejaron descendencia que vivía aún en la primera cuarta parte del siglo XVII. Como hemos seguido el modelo de Meléndez Chaverri (base de este listado), habrá un sesgo pues él no considera a las mujeres como fundadoras, solo bajo el concepto grupal de familia (aunque no necesariamente la hayan integrado como tal). Asimismo, si se considerara fundador a cada español que arribó en ese periodo, la cifra subiría considerablemente pues algunos llegaron con hijos varones y mujeres, como Alonso 
del Cubillo y Juan de Peñaranda, cuyos hijos no están en la presente lista.

(*) Aunque Meléndez Chaverri los incluye como fundadores, no los considero tales pues no hay prueba documental, ni indicios, de que hayan dejado sucesión en Costa Rica.

(**) Caso dudoso porque no hay pruebas contundentes de que sean fundadores.

(***) La filiación dada por Meléndez Chaverri es totalmente equivocada. Juan López Cerrato de Sotomayor fue hijo legítimo de Alonso Fernández de Córdoba Sotomayor y Da. Inés Cerrato [esta última hija legítima del Dr. Juan López Cerrato y María de Contreras, naturales de España, quienes también tuvieron un hijo nombrado Juan López Cerrato, vecino de Granada, Nicaragua]. Tampoco lo considero fundador.
(1) Se ignora cuándo ingreso a Costa Rica, pero sabemos que fue antes de 1599. Se le cita como poblador antiguo de la provincia.

Abreviaturas: A: entró con Anguciana de Gamboa; ART: entró con Artieda Chirinos; C: entró con Cavallón; CR: Costa Rica; Da.: doña; e: esposa; esp: natural de España; F: entró entre 1590 y 1599; gua: natural de Guatemala; hc: hija de conquistador; hond: natural de Honduras; mex: natural de México; mst: mestiza; nc: nieta de conquistador; nic: natural de Nicaragua; P: entró con Perafán de Ribera; por: portugués; VC: entró con Vásquez de Coronado; VR: entró con Venegas de los Ríos.

Fuente: Meléndez Chaverri (1982) e investigación propia de Mauricio Meléndez.

\section{APÉNDICE 2}

\section{Columnas Raíces}

Desde 1999, se edita la columna genealógica Raíces, en www.nacion.com (versión digital del diario La Nación, de Costa Rica). Es un espacio dedicado a la genealogía costarricense, que incluye trabajos propiamente genealógicos y aspectos teórico-metodológicos de esta disciplina (para algunos un simple pasatiempo, para otros auxiliar de la historia, para algunos obligación eclesiástica y para otros disciplina independiente).

Para llegar a la página principal de la columna digite: http://www.nacion.com/ln_ee/ESPECIALES/raices/

Para ingresar a cada una de las ediciones, cambie el final de la dirección según el número de la columna; si es la primera: .../raices1.html; si es la quinta: .../raices5.html; si es la vigésima: .../raices20.html; y así sucesivamente. Por ejemplo, si es la columna número 22, la dirección será: http://www.nacion.com/l n_ee/ESPECIALES/raices/raices22.html

Raíces $\mathrm{N}^{\mathrm{o}}$ 1: $\quad$ Nuestros orígenes.

Raíces $N^{\circ}$ 2: $\quad$ Algunas familias antiguas: los Arias, Barbosa, Barquero, Fallas y otras.

Raíces No 3: $\quad$ Los cambios de apellido durante la Colonia.

Raíces No 4: $\quad$ Centroamérica: Orígenes comunes.
Raíces $N^{\circ}$ 5: $\quad$ La investigación genealógica en Centroamérica.

Raíces Nº: Gracias a los piratas: Irlandeses en Costa Rica.

Raíces No 7: $\quad$ La familia Cartín.

Raíces No 8: De La Serena a la Boca del Monte: Inmigrantes chilenos en Costa Rica.

Raíces № 9: $\quad$ La familia Carrillo.

Raíces N $N^{\circ}$ 10: $\quad$ El Día de las Culturas y las raíces de los costarricenses.

Raíces $\mathrm{N}^{\mathrm{o}}$ 11: $\quad$ La genealogía e Internet.

Raíces No 12: $\quad$ El mundo y los bienes de una familia de la élite.

Raíces No 13: Los Montealegre de Costa Rica y Nicaragua.

Raíces N 14: Los Castro de Costa Rica.

Raíces No 15: El Archivo Eclesiástico de la Curia Metropolitana.

Raíces No 16: Los Alfaro de Costa Rica.

Raíces No 17: $\quad$ Los Conejo en Costa Rica.

Raíces No 18: Yolanda Oreamuno Unger.

Raíces $\mathrm{N}^{\circ}$ 19: $\quad$ Las raíces indígenas de los ticos.

Raíces No 20: $\quad$ La familia Díaz de San José. 
Raíces $\mathrm{N}^{\circ}$ 21: Heráldica: la ciencia del blasón.

Raíces No 22: La familia Echavarría Navarro (hoy Echeverría) en Costa Rica.

Raíces No 23: $\quad$ Primos y rivales: Rolando Araya, Antonio Alvarez, Rodolfo Méndez, Abel Pacheco y José Miguel Corrales.

Raíces No 24: $\quad$ Franceses en Costa Rica: La familia Carit.

Raíces № 25: Las Castas en Hispanoamérica.

Raíces No 26: El Archivo General de Centraomérica (en Guatemala).

Raíces $\mathrm{N}^{\circ}$ 27: A la sombra de un mismo árbol: Ottón Solís, Otto Guevara, Abel Pacheco y Rolando Araya son parientes.

Raíces No 28: $\quad$ Tesoro genealógico: La importancia de los expedientes matrimoniales.

Raíces No 29: México: El Archivo General de la Nación ofrece tesoros a centroamericanos.

Raíces No 30: De Portugal a Costa Rica: Orígenes de la familia Cambronero.
Raíces N ${ }^{0}$ 31: Chinos en Costa Rica: La familia Quirós Solano de Juan Viñas.

Raíces $N^{\circ}$ 32: Juan Bardales, negro esclavo: El conquistador desconocido.

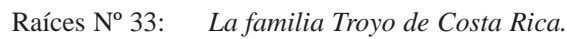

Raíces No 34: $\quad$ Los Chinchilla de San José.

Raíces No 35: De Fresnedos de Ibor, en Extremadura, a Cartago: La familia Barquero de Costa Rica.

Raíces No 36: De Extremadura, España, a Nicaragua y Costa Rica: La familia Rodríguez oriunda de Mérida.

Raíces No 37: $\quad$ Una familia León de Heredia.

Raíces No 38: Atenas: Tierra de centenarios.

Raíces № 39: $\quad$ La familia García Cordero y algunos de sus descendientes (1720-1870).

Raíces No 40: Ascendencia de la escritora Carmen Naranjo Coto (1928).

\section{APÉNDICE 3}

\section{Archivo Nacional de Costa Rica, Guatemala, N $^{\circ} 603$}

(Es una transcripción literal, únicamente se acentuaron algunas palabras y se modernizó la puntuación, para facilitar la lectura).

\section{Folio 1}

En la Villa Viexa [Heredia] a veinte de septiembre de mil septecientos noventa años por cuanto ante mi el capitán de milicias don Simón Escalante y Paniagua, alcalde ordinario de segundo voto de dicha villa, compareció doña Leonor de Alfaro, de esta vecindad, asiendome precente que su marido, don José Manuel Segura, se haya acsidentado segun se infiere poniendose demente, o fatuo, y que como a cargo de este se hayan siento setenta y ocho pesos en vienes raizes, muebles y semovientes pertenecientes a don Ramón Ulate, que por ygual acsidente la Real Justicia a pedimento de dicho su marido como medio hermano de Ulate procuró su seguridad con respicencia [sic] a tener hijos menores y ser viudo el conzavido don Ramón según consta de las diligencias practicadas a este efecto y de la escritura otorgada por el espresado don José Manuel Segura en que se obliga a tener y mantener los bienes del repetido Ulate durante su enfermedad esepto los que sus alimentos y bistuario gastase como su tutor, y que como ya por la enfermedad dicha que la a sobrevenido al enunciado Segura no puede administrar los vienes de Ulate como corresponde y subministrarle de ellos lo necesario como es obligado por su escritura me suplica que en méritos de justicia atendida su representación me sirva

\section{Folio 1 vuelto}

de yndennisarle de la obligación y poner los vienes en otro sugeto que los administre con la misma obligación que su marido los 
tenía en culla concecuencia y havida concideración a lo que esta parte representa digo que devo de mandar y mando se reciva ynformación sobre la enfermedad o demencia del enunciado Segura y con lo que de ella resultase se determinará lo que conbenga asi lo proveo, mando y firmo autuando con testigos por falta de escribano los que sertifico

\section{Simon Escalante y Paniagua [rubricado] Antonio Bonilla [rubricado] Ruperto Pérez [rubricado]}

Inmediatamente yo, el alcalde ordinario de segundo voto para la ynformación que se previene en el auto anterior, hize comparecer a don Baltasar de Alfaro, de este vecindario, a quien sertifico conosco y por ante los testigos con que autuo por falta de escribano le reciví juramento que hizo en la forma ordinario bajo cuyo cargo ofrecio desir verdad en lo que supiese y le fuese preguntado y siendo examinado sobre que diga si es sierta la enfermedad y demencia que le a sobrebenido a don José Manuel Segura, según espresa su mujer, doña Leonor de Alfaro, dijo que lo a tratado y comunicado con bastante cuidado procurando especular lo sierto de su enfermedad y segun el estado en que se haya dicho Segura lo que havla, pregunta y responde no hai duda en que está demente, fuera de juicio y que esta es

\section{Folio 2}

verdad en fuerza de juramento que se afirmo y ractificó leída su declaración espresando ser de setenta años y que aunque por ser su llerno Segura le tocan las generales de la lei no por eso a faltado a la religión del juramento, no firmó por no saver agolo yo con dichos testigos, lo que sertifico

\section{Simón Escalante y Paniagua [rubricado] \\ Antonio Bonilla [rubricado] \\ Ruperto Pérez [rubricado]}

Seguidamente, yo, el espresado alcalde, para la ynformación que se esta siguiendo, hize parecer a don Mariano Zamora, de este vecindario, a quien sertifico conosco y por ante los testigos con que autuo por falta de escribano, le reciví juramento que hizo en la forma legal bajo cuyo cargo ofreció desir verdad en lo que supiese y le fuese preguntado y siendo examinado por el mismo asunpto el anterior dijo que segun la especulacion que tiene echa de don José Manuel Segura sobre su enfermedad por lo que este abla, pregunta y responde, se conose estar demente, fuera de juicio, en conformidad de la suspención en que se mantiene y que cuanto produse en su conbersación es un mere desconcierto y desarreglo; y que esto es la verdad y cuanto puede declarar en el particular en fu-

\section{Folio 2 vuelto}

erza de juramento en que se afirmo y ratificó, leída su declaración espresando ser de cuarenta y tres años y que no le tocan las generales de la lei, firmó conmigo y idchos testigos, lo que certifico

\section{Simón Escalante y Paniagua [rubricado] \\ Mariano Zamora [rubricado] \\ Antonio Bonilla [rubricado] \\ Ruperto Perez [rubricado]}

Yncontinenti, yo, el espresado alcalde, para la ynformación de que se trata, hize conpareser a don José Manuel Gutiérrez, de este becindario, a quien sertifico conosco y por ante los testigos con que autuo en falta de escribano, le recibí juramento que hizo en la forma ordinaria vajo cuyo cargo ofreció decir verdad en lo que supiese y le fuese preguntado y siendo examinado por el mismo orden que los antecedentes dijo que a comunicado con bastante cuidado con don José Manuel Segura y según lo que este por su conberzación produse se aya demente, fuera de juicio y que esta es la verdad, en fuerza de su juramento en que firmó y ractificó, leída su declaración y espresó

\section{Folio 3}

ser de cuarenta y dos años y que no le tocan las generales de la lei, no firma por no 
saver, hagolo yo con dichos testigos lo que certifico

\author{
Simón Escalante y Paniagua [rubricado] \\ Antonio Bonilla [rubricado] \\ Ruperto Perez [rubricado]
}

En la Villa Viexa, a veinteuno de septienbre de mil setecientos noventa años, yo, el capitán de milicias don Simón Escalante y Paniagua, alcalde ordinario de segundo voto de dicha villa y su jurisdicción, en vista de que por la ynformación anterior resulta que don José Manuel Segura se haya demente fuera de su juicio según asi lo deponen los testigos examinados en la sumaria y como a cargo de este están los vienes de don Ramón Ulate, que por ygual enfermedad se pucieron a su quidado para que los administrase en clase de tutoría como así costa de la escritura de obligación que a tener y man-

\section{Folio 3 vuelto}

tener y dar cuentas otorgó dicho Segura en mi protocolo corriente y asiendose como se haze presiso remover la tutoría y tenencia de dichos vienes del poder del conzavido don José Manuel a cauza del acsidente que padese en esta virtud y la de tener el enunciado Ulate dos medios hermanos que son don Miguel y don Trinidad Herrera, nombro a estos por tutores y tenedores de los repetidos vienes pertenecientes al repetido don Ramón Ulate para que los tengan y mantengan en su poder durante su enfermedad subministrándole de ellos lo necesario para sus alimentos y bestuario; y este nombramiento póngase en ynteligencia de los dichos Herreras para que otorguen la correspondiente escritura asi lo proveo, mano y firmo por ante los testigos con que autuo en falta de escribano, lo que certifico.

Simón Escalante y Paniagua [rubricado]

Antonio Bonilla [rubricado]

Ruperto Perez [rubricado]
[Al margen izquierdo: Noticiación]

Yncontenineti yo, el alcalde ordinario jues de estas diligencias notifiqué e yze saver

\section{Folio 4}

la providencia anterior a don Miguel y don Trinidad Herrera, medio hermanos de don Ramon Ulate, y enterados dixeron que se arán cargo de los vienes de que se trata y que otorgarán escritura obligándose a tenerlos y mantenerlos en la forma que el la [sic] Providencia se previene esto respondieron y firmó conmigo el que supo, lo que certifico.

\section{Paniagua [rubricado]}

Villa Viexa y septiembre 22 de 1790

Tásance las costas de estas diligencias para que le satisfagan los vienes de don Ramon Ulate y deducidas estas y lo gastado por don Jose Manuel Segura en la manutencion del dicho Ulate de lo liquido otorgaran la escritura los tutores nombrados por mi asi lo proveo y firmo yo el alcalde ordinario de segundo voto por ante los testigos con que a autuo por falta de escribano lo que certifico.

Simon escalante y Paniagua, rubricado.

Ant $^{\circ}$ Bonilla, rubricado.

Ruperto Perez, rubricado.

Incontinenti, yo, el jues de estas diligencia, paso a formar la tasacion que en el auto anterior se previene en la manera si

\section{Folio 4 vuelto}

guiente.

Primeramente por dos autos a seis reales cada uno, un peso y cuatro reales $\quad 14$ Por tres declaraciones llanas a cuatro reales, un peso y cuatro reales 14 Por el nombramiento de tutores, 6 reales 6 
Por una notificación en el jusgado, dos reales 2 Por la escritura que an de otorgar los tutores dies i ocho reales, 22

Por siete firmas de mi dicho jues, a real, 7 reales 7

Por dos pliegos de papel del sello tercero, cuatro reales 4
Por esta tasacion, 4 reales 4

Con cuya partida se concluyo esta tasacion que, segun de la suma, parese ynporta ocho pesos y un real salvo llerro y para que conste lo firmo.

Paniagua, rubricado. 